\title{
Government as the First Investor in Biopharmaceutical Innovation: Evidence From New Drug Approvals 2010-2019
}

\author{
Ekaterina Galkina Cleary, Matthew J. Jackson, and \\ Fred D. Ledley ${ }^{1}$
}

\section{Working Paper No. 133}

\author{
August 5 $5^{\text {th }}, 2020$
}

\begin{abstract}
The discovery and development of new medicines classically involves a linear process of basic biomedical research to uncover potential targets for drug action, followed by applied, or

\footnotetext{
${ }^{1}$ Center for Integration of Science and Industry, Departments of Natural \& Applied Sciences, Mathematical Sciences, and Management, Bentley University, Waltham MA. Corresponding author: Fred D. Ledley, Center for Integration of Science and Industry, Jennison Hall 143, Bentley University, 175 Forest Street, Waltham, MA 02452. Tel: 781.891.2046; email: fledley@bentley.edu. Center for Integration of Science and Industry at Bentley University www.bentley.edu/sciindustry @ sciindustry
}

The Institute for New Economic Thinking provided funding for this research through a grant to Bentley University. Additional funding was supported by the National Biomedical Research Foundation through a grant to Bentley University. The authors would like to acknowledge the contributions of Kevin Zhang, Prateet Shah, Dr. ZoeFolchman-Wagner, Dr. Andrew Acevedo, Dr. Franklin Bright, Dr. Nusrat Rahman, and Clifton Chow, data generated by Dr. Heidi Williams, as well as discussions with Dr. Bill Lazonick, Dr. Öner Tulum, Dr. Michael Boss, and Dr. Nancy Hsiung. Portions of this work by Prateet Shah were submitted in fulfillment of an Honors Capstone Project requirement at Bentley University (May 2020). The authors report no conflicts of interest. This work did not receive funding from the NIH. 
translational, research to identify candidate products and establish their effectiveness and safety. This Working Paper describes the public sector contribution to that process by tracing funding from the National Institutes of Health (NIH) related to published research on each of the 356 new drugs approved by the U.S. Food and Drug Administration from 2010-2019 as well as research on their 219 biological targets. Specifically, we describe the timelines of clinical development for these products and proxy measures of their importance, including designations as first-inclass or expedited approvals. We model the maturation of basic research on the biological targets to determine the initiation and established points of this research and demonstrate that none of these products were approved before this enabling research passed the established point. This body of essential research comprised 2 million publications, of which 424 thousand were supported by 515 thousand Funding Years of NIH Project support totaling \$195 billion. Research on the 356 drugs comprised 244 thousand publications, of which 39 thousand were supported by 64 thousand Funding Years of NIH Project support totaling \$36 billion. Overall, NIH funding contributed to research associated with every new drug approved from 2010-2019, totaling \$230 billion. This funding supported investigator-initiated Research Projects, Cooperative Agreements for government-led research on topics of particular importance, as well as Research Program Projects and Centers and training to support the research infrastructure. This NIH funding also produced 22 thousand patents, which provided marketing exclusivity for $27(8.6 \%)$ of the drugs approved 2010-2019. These data demonstrate the essential role of public sector-funded basic research in drug discovery and development, as well as the scale and character of this funding. It also demonstrates the limited mechanisms available for recognizing the value created by these early investments and ensuring appropriate public returns. This analysis demonstrates the importance of sustained public investment in basic biomedical science as well as the need for policy innovations that fully realize the value of public sector investments in pharmaceutical innovation that ensure that these investments yield meaningful improvements in health.

\section{https://doi.org/10.36687/inetwp133}

JEL Codes: G35, H1, H4, H5, L2, O3.

Keywords: innovation, basic research, translational science, technology transfer, NIH funding, Bayh-Dole, public policy, federal funding. 


\section{Table of Contents}

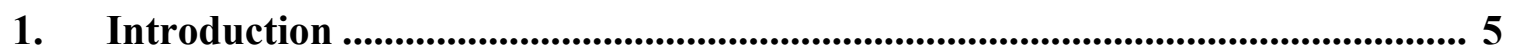

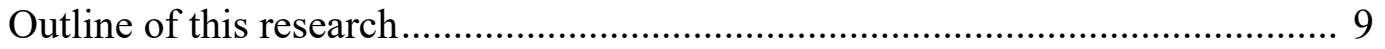

2. Background and Literature .............................................................................. 13

The linear model of biopharmaceutical innovation and role of the NIH............. 13

Defining the contribution of the public sector to biopharmaceutical innovation.. 19

The role of Bayh-Dole in realizing the public value of science ......................... 24

3. Research Results and Discussion.................................................................. 29

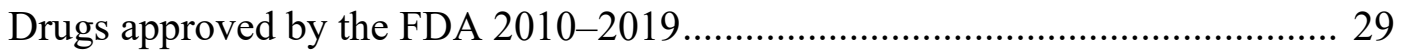

Measures of innovativeness............................................................................ 32

Modeling technology maturation................................................................ 35

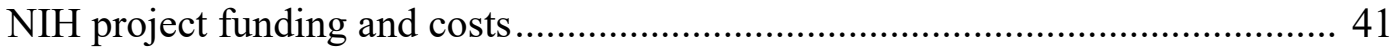

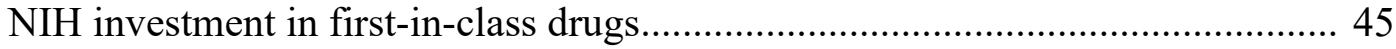

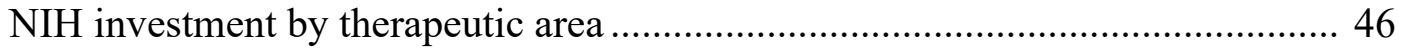

Research activities funded by the NIH ......................................................... 47

$\mathrm{NIH}$-funded patents associated with approved drugs ................................... 49

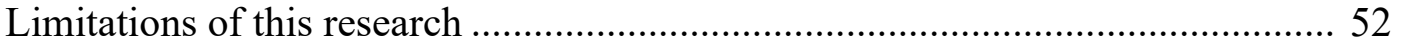

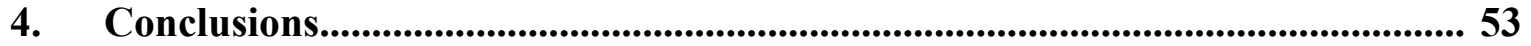

Appendix......................................................................................................................... 62

References...................................................................................................................... 63 


\section{Figures}

\section{Figures and Tables}

Figure 1. Schematic of drug discovery and development process.

Figure 2. Schematic of basic research maturation and the TIME model.

Figure 3. Annual FDA approvals, 2010-2019.

Figure 4. Percentage of NMEs in different therapeutic areas approved from 2010-2016 or 2017-2019.

Figure 5. Clinical trial start dates for NMEs approved 2010-2019.

Figure 6. Percentage of NMEs categorized as first-in-class, 2010-2019.

Figure 7. Expedited approval designations for new drugs approved 2010-2019.

Figure 8. Time from technology initiation (Ti) or technology established (Te) points to first approval, 2010-2019.

Figure 9. Time of first NME approval after established point (Te) of research on the drug target.

Figure 10. Number of PMIDs, NIH-funded PMID, NIH Funding Years, and project Costs associated with research on 356 NMEs approved 2010-2019 or their biological targets.

Figure 11. Funding Years and Project Costs associated with different forms of NIH funding since 2000.

Figure 12. Number of patents issued/year citing NIH funding also associated with published research on drugs approved 2010-2019 or their biological targets.

\section{Tables}

Table 1. Product class and FDA expedited drug status of New Molecular Entities (NMEs) approved by the FDA from 2010-2019.

Table 2. Years from R\&D milestones to approval for NMEs approved 2010-2019.

Table 3. Duration of clinical development from Phase 1 to approval for NMEs with trials initiated before the underlying technology passed the established point and after that point.

Table 4. Research publications, NIH Funding Years, and Project Costs associated with 356 NMEs approved by the FDA from 2010-2019 or their molecular targets.

Table 5. Funding Years and NIH Costs associated with 136 first-in-class products.

Table 6. Funding years and Costs associated with published research for NMEs approved 2010-2019 by therapeutic area.

Table 7. Identification of NMEs approved 2010-2019 with patents in the Orange Book funded by NIH-funded Projects also supporting published research on the NMEs or their biological targets.

Table 8. Percentage of NMEs approved 2010-2019 with patents in the Orange Book funded by NIH-projects also supporting published research on the NME or its biological target. 


\section{Introduction}

“...the highest attainable standard of health is one of the fundamental rights of every human being without distinction of race, religion, political belief, economic or social condition."

Constitution of the World Health Organization (WHO, 2006)

With these words, written in 1946, the post-war community of nations adopted the principle that health was a fundamental human right. The document went on to charge governments with "responsibility for the health of their peoples," and also noted that "the achievement of any State in the promotion and protection of health is of value to all' (WHO, 2006).

In the 75 years since this declaration, biopharmaceutical innovation has come to play an increasingly central role in protecting health and treating disease. Inspired, in part, by the wartime success of penicillin and sulfa drugs, medicine increasingly turned to the discovery and development of novel pharmaceutical products as a means for treating and preventing disease and improving health. In a series of studies on the impact of novel pharmaceutical products on human health starting in the late 1980s, Frank Lichtenberg estimated that drugs approved between 1986 and 2000 accounted for an increase in longevity of 0.8 years by 2000 (Lichtenberg, 2005), and that drugs approved after 1990 had contributed to an increase in longevity of 1.27 years by 2009 , representing $70 \%$ of the total increase in longevity over the same period (Lichtenberg, 2014a). His work has also suggested that pharmaceutical products improved population health, as measured by the number of work loss days, school loss days, and hospital admissions (Lichtenberg, 2014b), and improved "activities of daily living" among the elderly (Lichtenberg, 2012). Moreover, many pharmaceuticals were shown to be effective in reducing healthcare costs by preventing disease or obviating more expensive treatments or 
hospitalizations (Neumann et al., 2000). By 2018, the increasing use of medicines had created a global market for pharmaceutical products of more than $\$ 1.2$ trillion annually (Aitken \& Kleinrock, 2019). In the United States, prescription sales in 2018 totaled $\$ 476.2$ billion, representing 10\% of total healthcare spending (Schumock et al., 2019).

Government and industry both have critical roles in pharmaceutical innovation. As will be described in more detail in Section 2, contemporary science policy in the United States largely operationalizes a linear model of innovation, in which basic science, or use inspired basic science, performed in academic institutions and funded by the government provides fundamental insights or inventions, which are then transferred to industry for practical, commercial applications. The archetype of this model is the American government's Advanced Research Projects Administration (ARPA, now DARPA), whose pioneering work in information technology, computing and communications played a critical role in spawning the technology industry (Azoulay et al., 2019; Hafner \& Lyon, 1998; Lazonick, Mazzucato, \& Tulum, 2013).

A similar model has been evident in drug discovery and development. Government-funded, basic research has been shown to play a foundational role in pharmaceutical development (Comroe \& Dripps, 1978; Toole, 2012). Our previous work has shown that NIH funding contributed to research underlying every one of the 210 new drugs approved from 2010-2016, representing an investment of more than $\$ 100$ billion (2000-2016) (Cleary et al., 2018; Cleary \& Ledley, 2020). That work also showed that more than $90 \%$ of this funding was related to research on the biology underlying novel pharmaceutical products, rather than the drugs themselves (Cleary et al., 2018).

Virtually all of the pharmaceutical products on the market today, however, were developed and commercialized by for-profit companies (Kinch et al., 2014). Biopharmaceutical companies 
invest an average of more than a billion dollars in the development of each new, approved product (DiMasi, Grabowski, \& Hansen, 2016; Wouters, McKee, \& Luyten, 2020) and are responsible for the manufacture and marketing of these products after approval.

This work was undertaken in the context of existential threats to both the public and private sector funding for the basic biomedical research that enables drug discovery and development. The threat to public sector funding for basic science has been acutely evident in recurring proposals from the Executive Branch to cut the budgets of the National Institutes of Health (NIH), National Science Foundation (NSF), and science programs at other agencies (Mervis, 2020a). While Congress has consistently resisted recent attempts to reduce the NIH budget (Mervis, 2020b), there is a significant long-term trend towards reduced public investment in research and development throughout the OECD countries (Archibugi \& Filippetti, 2018). Moreover, continued growth of non-discretionary spending in the coming decades will leave a smaller proportion of the federal budget available for discretionary spending, including biomedical research (Hourihan, 2018).

Private sector funding of early-stage basic or applied research by the pharmaceutical industry is also under threat from several factors. One is the increased financialization of the pharmaceutical industry and its focus on maximizing shareholder value, which has reduced corporate investment in institution learning (Lazonick et al., 2017; Lazonick, Mazzucato, \& Tulum, 2013; Lazonick \& Tulum, 2011; Montalban \& Sakinç, 2011, 2013; Tulum \& Lazonick, 2018). The impact of financialization has been exacerbated by the increasing cost of biopharmaceutical research and decreasing return on investment (Pammolli, Magazzini, \& Riccaboni, 2011; Scannell, Blanckley, Boldon, \& Warrington, 2012; Steedman \& Taylor, 2020), which have made such investment in research less attractive to shareholders. 
Industry investment in $R \& D$ is further threatened by potential policy initiatives designed to reduce drug prices (Padula, 2019; Sachs, 2019). The prices of pharmaceutical products have risen sharply in recent decades, and there is growing concern that drug prices now limit their availability to those who need these products (Deb \& Curfman, 2020; Hernandez et al., 2020; Kesselheim, Avorn, \& Sarpatwari, 2016; NAS, 2018). Moreover, many of the largest pharmaceutical companies are highly profitable. Our research has shown that from 2000-2018, 35 of the largest pharmaceutical companies had cumulative revenue of $\$ 11.5$ trillion and net income (earnings or profits) of $\$ 1.9$ trillion, and were significantly more profitable than other companies in the S\&P 500 (Ledley et al., 2020). While policies might be developed that balance the affordability of drugs with sustained innovation, previous studies showed that the Clinton-era initiatives aimed at reducing drug prices were associated with lower R\&D spending in the pharmaceutical industry during the years these policies were being considered (Abbott \& Vernon, 2007; Giaccotto, Santerre, \& Vernon, 2005; Golec, Hegde, \& Vernon, 2010; Vernon, $2005) .^{2}$

This research was undertaken in the context of government's "responsibility for the health of their peoples" and its vested interest in sustained biopharmaceutical innovation as one means of providing the "the highest attainable standard of health." To the extent that novel pharmaceutical products contribute to achieving a higher standard of health and represent public value, this work provides insights into the broader concept of government as an "investor of first resort” in value creation (Block \& Keller, 2015; Hopkins \& Lazonick, 2014; Lazonick, 2017;

\footnotetext{
${ }^{2}$ The Congressional Budget Office provided preliminary analyses of the effects of H.R.3 on pharmaceutical innovation in letters dated October 11, 2019 (https://www.cbo.gov/system/files/2019-10/hr3ltr.pdf) and December 10, 2019 (https://www.cbo.gov/system/files/2019-12/hr3 complete.pdf). These analyses variously estimate that H.R.3 could lead to 8-15 fewer drugs coming to market (October, 2019) or as much as 10\% (December, 2019).
} 
Lazonick \& Mazzucato, 2013; Mazzucato, 2011, 2016; Mazzucato \& Semieniuk, 2017) as well as the "risk-reward nexus" that results in an unequal distribution of risk and reward between the public and private sector (Lazonick \& Mazzucato, 2013).

This has created a critical need for a greater understanding of the role played by government in the biopharmaceutical innovation process, how value is created and returned through this process, and how to maximize the health benefits of this work. Given the rapidly changing landscape of biopharmaceutical innovation and public concern about the affordability and availability of medicines, as well as the acute health and economic shocks associated with the COVID-19 pandemic, there is an opportunity to apply evidence-based policies that leverage the role of government to promote effective innovation and value creation now and in the future.

\section{Outline of this research}

Section 2, Background and Literature, begins with a brief description of the linear model of innovation, which has long provided a conceptual framework for the biopharmaceutical innovation ecosystem. This classical model, which posits a directional flow of innovation from basic research $\rightarrow$ applied research $\rightarrow$ development $\rightarrow$ products and services, underlies much of the research on biopharmaceutical innovation and strategy, the process of drug development and regulatory review by the U.S. Food and Drug Administration (FDA), and the design of the BayhDole Act. We describe the meaning of "basic" and "applied" research in this model, the differentiated roles of the public and private sector, and amendments to the classical model, with particular recognition of the role played by "use-inspired" basic research. To aid understanding, we also provide a short overview of the process for drug discovery and development, and 
regulatory classifications of novel drug products related to their innovativeness and approval path.

We also provide an overview of the Bayh-Dole Act, as well as its impact on the biopharmaceutical innovation ecosystem. A complete review of the extensive literature on the Bayh-Dole Act and its impact is beyond the scope of our analysis. Our overview focuses on several key issues. First, we discuss the policy goals underlying the design of the Bayh-Dole Act. Second, we discuss the process of technology transfer/licensing by academic institutions. Finally, we consider the role of patents in the mechanisms for value creation and capture established by the Bayh-Dole Act. Specifically, we ask whether the restriction of Bayh-Dole to patentable results of government-funded research limits its applicability to promoting public value creation.

Section 3, Research Results and Discussion, describes our research in several discrete stages. The first step involved identifying and characterizing the new drugs (New Molecular Entities [NMEs]) approved from 2010-2019. We describe 356 products approved during this decade, their characteristics, biological targets, applications, and measures of the innovativeness or importance. The second step involved performing literature searches in the PubMed database to identify published literature directly related to either these drugs or their biological targets. We then used the Technology Innovation Maturation Evaluation (TIME) model to estimate when these bodies of research passed the established point of research maturation. Previous work has shown that an established body of research on novel targets is requisite for efficient drug development. Third, we use the NIH RePORTER database to identify published research arising from NIH grants, the specific grants (Programs), fiscal years (Funding Years), and Project Costs contributing to this research, and the patents that arose from the research results. Fourth, we describe several proxy measures for the innovativeness or importance of the new drugs approved 
over this decade including first-in-class designations, and designations for expedited review and approval. Fifth, we examine the patents identified in the FDA Orange Book as providing exclusive marketing rights for approved products, and ask how many of these patents arose from the NIH funding and research detailed in this report.

Section 4, Conclusions, provides a brief discussion of the potential implications of this research for understanding the biopharmaceutical innovation ecosystem and formulating evidence-based policy to achieve "the highest attainable standard of health" and maximize public value creation. We also discuss the limitations of our methods and analysis, as well as areas for future research.

We want to express our particular gratitude to the Institute for New Economic Thinking for its support of this work and to Dr. Thomas Ferguson and Dr. William Lazonick for encouraging us to consider the larger economic policy implications of our work. This Working Paper describes a core dataset and analysis of the new drugs approved during the decade 2010-2019 as well as the substantial public sector investments made by the NIH that enabled the discovery and development of these products. These data describe the current state-of-the-art for drug development, factors that contribute to the persistently long timelines and high failure rate of discovery and development, the scope of the public sector investment in this process, and factors that limit the public's control over the products and the value created by these investments. The work has implications for accelerating the translation of scientific discoveries for public value and formulating policies to ensure that science is used to achieve "the highest attainable standard of health" in a way that is both efficient and equitable. None of these issues are addressed in sufficient detail in this Working Paper; each requires far deeper consideration of the relevant literature and more complete analysis in the future. We are acutely aware of these limitations, 
and look forward to productive discussions with readers who may find our consideration of these inadequate and identify areas for future investigation. 


\section{Background and Literature}

\section{The linear model of biopharmaceutical innovation and role of the NIH}

The process of discovering and developing new medicines is classically described in terms of a linear model of innovation. In its simplest form, the model posits that there is a directional, "linear" flow of progress towards innovation from basic science, through applied science, and finally to the development and commercialization of novel products and services (Balconi, Brusoni, \& Orsenigo, 2010; Edgerton, 2004; Godin, 2006). The linear model posits that there is a clear distinction between "basic" research, "applied" research, and development. "Basic research” is defined by the National Science Foundation (NSF) as being “...undertaken primarily to acquire new knowledge of the underlying foundations of phenomena and observable facts, without any particular application or use in view," and is distinct from applied research, defined as being “...directed primarily towards a specific, practical aim or objective.” The penultimate step is development, defined as being “...directed to producing new products or processes or to improving existing products or processes" (NSF, 2018), which leads to commercialization. The concept of "basic science" has been extended by recognizing the role of "use-inspired basic research", which is undertaken without specific products or processes in mind, but with the purpose of advancing economic gains or the public good (Stokes, 2011).

In biomedical research, the term "translational research," is also used, which pertains to “...applying discoveries generated during research in the laboratory, and in preclinical studies, to the development of trials and studies in humans" (NIH, 2007). Translational research is most commonly undertaken in conjunction with assessing the safety and efficacy of specific medical products or interventions. 
The linear model of innovation has been subject to intense analysis and criticism (Balconi et al., 2010; Godin, 2006). Nevertheless, the model had a central role in US science policies and an important imprint on the process of pharmaceutical development.

The influence of the linear model on US science policy dates from the work of Vannevar Bush and his 1945 report titled The Endless Frontier (Bush, 1945; Godin, 2006). This report recognized that the war effort had created "a unique experiment of team-work and cooperation in coordinating scientific research and in applying existing scientific knowledge to the solution of the technical problems" that could also be applied to the public welfare including the "war of science against disease." Bush noted: "Penicillin reached our troops in time to save countless lives because the Government coordinated and supported the program of research and development on the drug. The development moved from the early laboratory stage to large scale production and use in a fraction of the time it would have taken without such leadership."

Bush's model for US science policy created a sharp distinction between basic and applied science, familiar to the linear model of innovation. He defined basic science as being “...performed without thought of practical ends...," presaging language that would become embedded in the NSF definitions. ${ }^{3}$ His science policy was predicated on the expectation that: "Basic research leads to new knowledge. It provides scientific capital. It creates the fund from which the practical applications of knowledge must be drawn." He then anticipates that "Industry

\footnotetext{
3 "Basic research is performed without thought of practical ends. It results in general knowledge and an understanding of nature and its laws. This general knowledge provides the means of answering a large number of important practical problems, though it may not give a complete specific answer to any one of them. The function of applied research is to provide such complete answers. The scientist doing basic research may not be at all interested in the practical applications of his work, yet the further progress of industrial development would eventually stagnate if basic scientific research were long neglected." (Bush, 1945)
} 
will fully rise to the challenge of applying new knowledge to new products. The commercial incentive can be relied upon for that" (Bush, 1945).

He goes on to localize the basic research enterprise outside of industry, writing: "Publicly and privately supported colleges and universities and the endowed research institutes must furnish both the new scientific knowledge and the trained research workers. These institutions are uniquely qualified by tradition and by their special characteristics to carry on basic research." In contrast, he writes "Industry is generally inhibited by preconceived goals, by its own clearly defined standards, and by the constant pressure of commercial necessity. Satisfactory progress in basic science seldom occurs under conditions prevailing in the normal industrial laboratory." Recognizing the distinct enterprises involved in basic and applied research, Bush recommended that "...basic research should be strengthened by use of public funds" provided to colleges, universities and research institutes, and that the government should "devise and promote the use of methods of improving the transition between research and its practical application in industry (Bush, 1945).

Three decades later, this model of medical innovation would be evidenced in the design of the "War on Cancer." The 1971 act called for investments primarily in basic science related to mechanisms of normal and abnormal cell growth and differentiation based on "the assumption that unbiased fundamental research would hold the key to unlocking the secrets of cancer" (Haber, Gray, \& Baselga, 2011). While it would be thirty to forty years before this research was sufficiently mature to generate effective cancer therapies (McNamee \& Ledley, 2017), the large number of anticancer drugs approved in recent years can be directly traced to basic research originated during that period (Cleary \& Ledley, 2020; McNamee \& Ledley, 2017). 
The linear model of innovation is deeply entrenched in the process of contemporary, targeted drug discovery and development. A typical schematic of the "targeted" drug discovery process is shown in Figure 1. In this model, drug discovery is enabled by a body of basic biomedical research that describes essential mechanisms of human biology and disease. This basic research delineates specific pathways for both disease and healing, and identifies the proteins that carry out essential functions on these pathways. This research also suggests strategies by which a chemical drug or manufactured protein might be targeted to a specific protein, and by attaching itself to this target, disrupt the disease process or promote healing. ${ }^{4}$

This information is then utilized in applied, or translational, research to identify or design drugs

Basic research

Basic Science, Target Discovery
Applied (translational) research

Figure 1. Schematic of drug discovery and development process.

that interact with the target protein in order to achieve these effects and are safe for use in humans, assess whether these drugs are effective and safe in laboratory or animal models, and develop methods for saleable production and quality control of these products. Only when this preclinical research meets the standards established by regulatory agencies, such as the Food and Drug Administration (FDA) in the US or European Medicines Agency (EMA) in the EU, can the first clinical studies be performed in human subjects.

\footnotetext{
4 "Targeted" drug discovery is contrasted with "phenotypic" drug discovery, which involves isolating compounds from extracts of plants or microorganisms with known biological activities. "Phenotypic" compounds, or chemical modifications of these compounds, can enter development without prior knowledge of the biological target or mechanism of action.
} 
Clinical trials proceed in defined phases. Phase 1 trials are classically undertaken in a small number of healthy volunteers to assess the safety of escalating doses of the drug. If the drug is shown to have a reasonable safety margin, the product will enter into Phase 2 trials in larger numbers of patients for an initial assessment of the product's effectiveness and effective dose. Only when a suitable dose and clinical application are identified, do products enter into "pivotal" Phase 3 trials designed to rigorously establish the safety and effectiveness of the product compared to an established therapy or placebo. If Phase 3 trials demonstrate significant effects, application can be made to regulatory agency for marketing approval. Following approval, the regulatory agencies can request Phase 4 studies to confirm key findings related to efficacy or safety.

In the United States, basic biomedical research is funded primarily by the NIH (Collins et al., 2016; Moses et al., 2015), whose stated mission is "to seek fundamental knowledge about the nature and behavior of living systems and the application of that knowledge to enhance health, lengthen life, and reduce illness and disability" (www.nih.gov/about-nih/what-we-do/missiongoals). While the NIH allocates half of its research budget to "basic" science (Lauer, 2016), this research is essentially use-inspired, and undertaken with the expectation of bettering human health.

The NIH commitment to basic science is shaped by many competing priorities. Research funding from the NIH is not awarded by a central mechanism, but rather by individual Institutes, most of which have disease or demographic-specific missions. Moreover, the distribution of NIH funding is sometimes measured against the relative burden of disease in society to assess how closely its work is aligned with public needs (Gillum et al., 2011; Gross, Anderson, \& Powe, 1999). Thus, NIH research funding is implicitly tied to use-inspired fields of study. The NIH is 
also subject to congressional mandates for research earmarked to specific diseases or conditions, which requires funding to be explicitly linked to legislated goals (Sampat, 2012). It is worth noting that the NIH also supports applied biomedical research, clinical research, as well as research on medical and surgical practice.

The NIH awards grants to small businesses through Small Business Innovation Research (SBIR) mechanisms, which are designed to bridge the gap between basic research performed in academic settings, and the proof of principle experiments often required for commercialization (NRC, 2009). The NIH will also selectively conduct clinical trials with significant public health implications. In addition, the NIH has traditionally championed bench-to-bedside clinical research, though this role has declined significantly in recent decades (Nathan \& Nathan, 2016; Nathan \& Wilson, 2003). In recent years, there has been growing pressure on the NIH to participate in translational and applied research that is more directly related to clinical applications (Collins, 2011; Woodcock et al., 2014; Zerhouni, 2007), and work at the National Center for Advancing Translational Science (NCATS) is increasingly moving downstream to aid in drug discovery and preclinical analysis (Austin, 2018). There is also growing interest in the power of government-academic-industry partnerships to facilitate efficient translation of scientific advances into innovative products (Leydesdorff, 2000; Leydesdorff \& Etzkowitz, 1998; Tralau-Stewart et al., 2009).

While government and academic institutions are showing increasing interest in applied and translational research, large pharmaceutical companies have become progressively disengaged from direct involvement in basic research. Large pharmaceutical companies increasingly focus on late-stage development, manufacture, and product marketing, and are filling their product 
pipelines through acquisition of mature technologies, early-stage products, and nascent biotechnology companies (Wang, Plump, \& Ringel, 2015).

We would emphasize that the linear model of innovation does not fully capture the dynamic nature of the innovation ecosystem. For example, it does not account for the push and pull of new technological capabilities and market needs (Godin \& Lane, 2013), the interactions that occur at the boundary between the academic and commercial sectors (Cockburn \& Henderson, 1996), the contributions made to use-inspired basic research by scientists in the biotechnology and pharmaceutical industries (Chakravarthy et al., 2016; Reichert \& Milne, 2002; Zycher, DiMasi, \& Milne, 2010); or recent efforts to promote translational science in the public domain (Collins, 2011; Varmus, 2006; Woodcock et al., 2014). Nor does the linear model apply to the conception of the "entrepreneurial university" (Etzkowitz, 2016, 2017) or the notion of an integrated "triple helix" of government-university-industry involvement in innovation (Leydesdorff \& Etzkowitz, 1998). Nevertheless, as our data will confirm, all of the new drugs approved by the FDA over the past decade were developed and commercialized by industry.

\section{Defining the contribution of the public sector to biopharmaceutical innovation}

While the linear progression of biomedical science from basic research to applications is deeply integrated into the culture and organization of innovative activities, the classic work of Comroe and Dripps (1978) was the first to systematically establish this association by identifying the scientific foundation of major advances in cardiovascular medicine. A different approach was taken by Toole (2012), who showed a statistical association between NIH-funded basic research and new drug launches, with a $1 \%$ increase in NIH research being associated with a $1.8 \%$ increase in new drugs. 
Our research group has examined the relationship between the advance of research on the biological targets for new drugs and drug approvals using an analytical model of technology maturation - the Technology Innovation Maturation Evaluation (TIME) model (McNamee, Walsh, \& Ledley, 2017). The TIME model is based on patterns of innovation observed in many other fields, ranging from earth-moving equipment to computing and communications technologies. Namely, that there is a characteristic pattern of technological maturation, which can be modeled as a series of S-curves (Christensen, 1992, 1997; Foster, 1982; McNamee \& Ledley, 2012). It has also been observed that nascent or emerging technologies are rarely able to meet the needs of established markets, even though they embody disruptive potential and will eventually match, and displace established technologies in the market once they mature (Christensen, 1992, 1997). Without reviewing persistent controversies about the theories of disruption that arise from this observation, the essential observation that technology maturation is related to the ability of a technology to meet the requirements of the market is consistent with observations in systems engineering that technology readiness is a critical factor in product success (Clausing \& Holmes, 2010). The General Accounting Office has written “...no element is more important than having technology, advanced enough to meet requirements but also mature enough to be predictably managed, available at the start of the product development cycle. Maturing new technology before it is included on a product is perhaps the most important determinant of the success of the eventual product" (GAO, 1999).

McNamee and Ledley (2012) explored the application of this principle to biopharmaceutical development, positing that the FDA standards for safety, efficacy, and quality constituted the requirements of the market, and that the maturation of the underlying biomedical science would be requisite for achieving these demands. Using the cumulative number of publications on a 
biological target for a

Technology initiation Technology established

drug or class of

molecular entity as a

proxy for

technological

advance, McNamee

et al. showed that the

advance of these

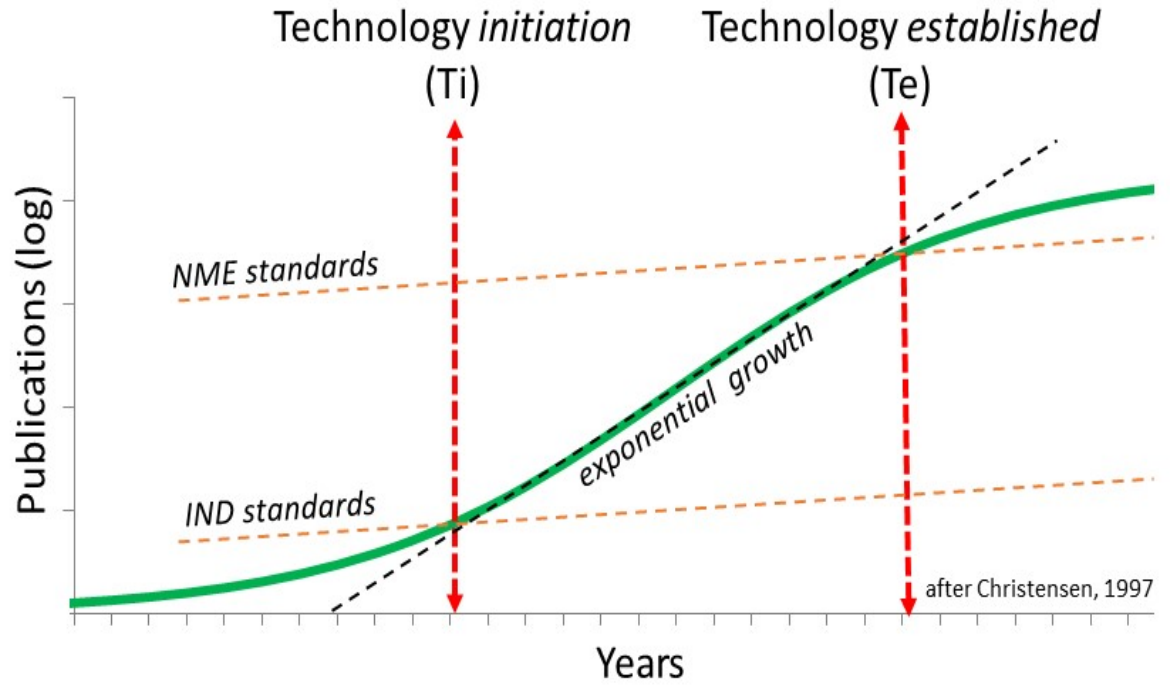

Figure 2. Schematic of basic research maturation and the TIME model.

technologies

followed a familiar S-curve pattern of maturation (McNamee \& Ledley, 2017; McNamee,

Walsh, \& Ledley, 2017). The TIME model fits the cumulative number of publications on a specific research topic to an asymmetrical, exponentiated logistic function (Appendix A). Plotted on a $\log$ scale (Figure 2), this function exhibits the characteristic, logistic "S-curve" of technology maturation models observed in other fields (Christensen, 1992; Foster, 1982). The TIME model identifies two inflection points specifically related to basic biological research and drug development (Figure 2). The calculated initiation point, or point of maximum acceleration of publication activity, corresponds to the date of early discoveries that lead to exponential growth in research activity. In a series of papers, McNamee et al. also showed that the calculated established point, or point of maximum slowing of publication activity, corresponds to a maturation threshold, before which few targeted therapeutics are successfully developed (McNamee \& Ledley, 2017; McNamee, Walsh, \& Ledley, 2017). These studies also showed that the duration of clinical trials is longer when these trials begin before the established point, and that the first products resulting from the basic research are approved an average of 14 years after 
this point (McNamee, Walsh \& Ledley, 2017). These results are consistent with the expectation that a mature body of foundational research is requisite for the efficient discovery and development of targeted therapeutics. Specifically, it suggests that while initial scientific insights or inventions may be sufficient for scientific publications, patents, or filings of Investigational New Drug (IND) applications to begin clinical trials, they are rarely sufficient to meet the requirements for new drug approval. A series of follow-on studies have extended this concept, showing that the first approval of targeted cardiovascular drugs, targeted cancer drugs, gene therapies, and nucleotide therapies all followed the maturation of the underlying basic biomedical research (Beierlein, McNamee, \& Ledley, 2017; Beierlein et al., 2017; Ledley et al., 2014; McNamee \& Ledley, 2017; McNamee, Walsh, \& Ledley, 2017).

Many studies, however, have shown a more limited impact of government-funded, academic research in products coming to market. Stevens et al. (2011) estimated that from 1990 to 2007 9.3\% of new drugs, as measured by the number of New Drug Applications (NDAs), were first patented in public sector research institutions and transferred to industry. This fraction is similar to estimates by Kaitin et al. (1993) that 7.6\% of drugs approved from 1981-1990 and 6.7\% of new drugs approved from 1990-1999 (DiMasi, Hansen, \& Grabowski, 2003) originated outside of industry (3.2\% in government, academic/nonprofits 3.5\%). Similarly, Sampat (2009) found that from 1988-2005, 7.7\% of all NDAs and 10.3\% of New Molecular Entities (NMEs) described in these NDAs, are based on university-owned patents cited in the FDA's Orange Book. Using a cohort approach, Nayak et al. described that 19\% of 248 new drugs approved from 2008-2018 had their origin in publicly supported research and development (Nayak, Avorn, \& Kesselheim, 2019). 
Sampat and Lichtenberg (2011) examined the prior art referenced in patents for new drug approvals, finding that from 1988-2005, 47.8\% of approvals were associated with a patent that cited prior art from the public sector (public sector patent or government publication), despite only $9 \%$ being directly associated with a public sector patent. These results are similar to those described by Patridge et al. (2015) who found that of the 1,453 drugs approved by the FDA through 2014, academic organizations were the first to publish the synthesis or purification of the compound for 801 (55\%), but filed the investigational new drug (IND) status for only $21(1.5 \%)$.

Case study methods generate similar results. Cockburn and Henderson (2000) examined the development of 21 drugs considered to have the most impact on practice from 1965-1992, finding that $76 \%$ were developed with some input from the public sector. Chakravarthy et al. (2016) examined the development of 19 of the "most transformative" drugs of the past 25 years, finding that, while only $15 \%$ of these drugs were discovered in the public sector, the public sector contributed to $54 \%$ of basic science milestones.

Our 2018 study by Cleary et al. looked explicitly at the contribution of NIH-funded basic science to new drugs approved from 2010-2016. That study identified more than 2 million research publications in the biomedical literature (PubMed) in this interval related to the 210 drugs approved or their 151 biological targets. Of these publications, more than 600,000 (29\%) cited federal research support comprising more than 200,000 fiscal years of project funding (19852016) and more than $\$ 100$ billion in project costs since 2000 . Significantly, NIH-funded research was identified in association with every new drug approved from 2010-2016.

Cleary et al. also demonstrated that more than $90 \%$ of the NIH-funded research was associated with basic science publications on the biological targets rather than the drugs. In contrast, less 
than $10 \%$ of the NIH funding was associated with applied (or translational) science for these specific drugs (Cleary et al., 2018). All of these products were subsequently developed and commercialized by for-profit, biopharmaceutical companies.

In a follow-on study of the 59 new cancer drugs included in the original analysis, Cleary and Ledley (2020) noted that the total amount of NIH funding attributable to research on these drugs or their biological targets approached, or exceeded, the total budgets of the National Cancer Institute (NCI) and the NIH's own estimate of spending on cancer research in the Research Condition and Disease Categorization (RCDC) database. Their analysis showed that much of the foundational research for new cancer drugs was, in fact, funded by institutes with other diseasefocused missions including the NIAID, NHLBI, and NIDDK. This suggested that "basic" research in areas such as immunology, funded by institutes focused on immune diseases such as allergy, blood diseases, or arthritis, contributed to the foundational research underlying new cancer therapies (Cleary \& Ledley, 2020). Such “spillover" effects are the result of the government's ability to invest in broad-based, basic research that is not restricted to specific product applications.

\section{The role of Bayh-Dole in realizing the public value of science}

Passage of the Bayh-Dole Act of $1980,{ }^{5}$ operationalized the "transition between research and its practical application in industry" anticipated by The Endless Frontier and the linear model of innovation. Bayh-Dole did this by authorizing public sector institutions and small businesses to patent and retain inventions made with federally-funded research, and allowing these institutions,

\footnotetext{
${ }^{5}$ The Bayh-Dole Act is Public Law 96-517, titled the Patent and Trademark Law Amendments Act, and is codified in 35 U.S.C. 200-212 and 37 CFR 401. https://grants.nih.gov/grants/bayh-dole.htm
} 
as well as the government, to enter into exclusive license agreements with private sector companies for development and commercialization, subject to a patent rights clause (NRC, 2011; Sampat, 2009; Stevens, 2004). Over the past forty years, Bayh-Dole has become a much practiced, criticized, and imitated keystone of the innovation ecosystem, particularly for biopharmaceutical products (Loise \& Stevens, 2010; Mowery \& Sampat, 2004; NRC, 2011; Stevens, 2004).

Prior to Bayh-Dole, inventions/discoveries made under federally-funded research were formally the property of the government. Prior to the 1960s, government was not the major source of funding for academic research, and more than $75 \%$ of Carnegie research universities entrusted the patenting and licensing of university research to an independent entity, the Research Corporation (Sampat, 2009). As government funding for academic research grew through the 1960s and 1970s, it was recognized that advances were being made that were patentable and of interest to industry, and systems were developed for universities to individually enter into Institutional Patent Agreements (IPA) with the government (Mowery \& Sampat 2004). Each government agency was empowered to develop its own patent policies consistent with their distinct missions, which led to wide variation in the terms of IPAs between different agencies and institutions (Sampat, 2009). Moreover, the government commonly granted only nonexclusive licenses, which often did not align with the interests of industry (Loise \& Stevens, 2010). In 1976, the Federal Council for Science and Technology estimated that only 5\% of the 28,000 patents owned by the federal government had been licensed (FCST, 1968; Sampat, 2006), at a time when policy makers were searching for ways to stimulate the American economy (Stevens, 2004). This was recognized to be an inefficiency that could be preventing American industry, and consequently taxpayers, from capitalizing on groundbreaking research. 
Bayh-Dole created a uniform policy allowing institutions receiving federal research funding to patent the results of this research and issue exclusive licenses. Institutions were expected to have agreements with their faculties and staff that required the disclosure of federally-funded inventions to the university and assignment of their rights to the institution. Institutions then had the option of patenting the invention at their own expense, or returning the rights to the inventors or licensing the resulting patents to industry for development. The federal government retains a "nonexclusive, nontransferable, paid-up license" to the invention as well as "march-in rights." March-in rights give the government the ability to grant itself a license to the invention when the institution or its licensee does not take "effective steps" to practice the invention or in response to health, safety, or other "public use specified by federal regulations" that are "not reasonably satisfied" by the institution or licensee without direct government oversight (CFR, 2010; Thomas, 2016; Treasure, 2016). Patents resulting from government-funded research are also required to have a "government-interest" disclosure outlining the governments rights to that patent, and these patents are subject to various reporting requirements. Institutions were expected to have agreements with their faculties and staff that assigned the rights to government-funded inventions to the institution, and many set up technology transfer or licensing offices dedicated to the productive management of this intellectual property.

Implicit in the Bayh-Dole Act was the assumption that taxpayers would benefit from industrial development of licensed technologies in terms of the products, jobs, and economic growth that would result, that non-profit institutions would invest the proceeds from technology licensing in the public interest consistent with their charters, and that the growth of small businesses, which were considered to be the wellspring of innovation and economic growth, would be promoted. 
As a practical matter, patents are central to the structure of the Bayh-Dole Act and, thus, the assignment and licensing of the intellectual property rights resulting from government-funded research governed by that Act. ${ }^{6}$ For the results of a research project to be patentable, they must meet five criteria: (1) describe patentable subject matter; (2) utility; (3) novelty; (4) nonobviousness; and (5) enablement.

Not all research, however, is designed to meet these standards. Specifically, patent law requires the inventor to recognize a functional purpose or usefulness of the invention, and also provide sufficient information to enable those "skilled in the art to reduce it to practice without the exercise of extensive experimentation or the exercise of inventive skill." As such, pure "basic" research that undertaken "without any particular application or use in view" implicitly may not meet the utility requirement. Moreover, given the complexity of translating biological discoveries into clinical applications (Collins, 2011), such discoveries often require "extensive experimentation" and "inventive skill” and may not satisfy the standards of enablement.

Li, Azoulay, and Sampat have demonstrated that only $8.4 \%$ of NIH grants generate a patent directly, but that $31 \%$ generate results that are cited as "prior art" in subsequent grant applications. They conclude that the greatest impact of NIH funding is not captured directly by patents, but rather indirectly by creating "art" that leads to the invention (without making it obvious) or enables the invention to be practiced (Li, Azoulay, \& Sampat, 2017). They also

\footnotetext{
${ }^{6}$ Other forms of intellectual property arising from basic research may include trade secrets and know-how (an intangible, intellectual property right). These are defined as: Trade Secrets: "Information, including a formula, pattern, compilation, program, device, method, technique, or process that: (i) Derives independent economic value, actual or potential, from not being generally known to, and not being readily ascertainable by proper means by, other persons who can obtain economic value from its disclosure or use; and (ii) Is the subject of efforts that are reasonable under the circumstances to maintain its secrecy" (https:/www.law.cornell.edu/wex/trade secret); and Know-how: "The ability to achieve a practical end due to knowledge and/or skill" (https://www.law.cornell.edu/wex/know-how).
} 
found that less than $1 \%$ of NIH grants are directly acknowledged by a patent associated with a marketed drug in the FDA Orange Book, ${ }^{7}$ but $5 \%$ of grants result in publications that represent art for drug patents.

Their work also assessed the "basicness" of the NIH-funded research using a rubric with four criteria: "whether the research is disease-oriented, whether it is focused on patients, and whether it is solicited by the funder or is investigator-initiated; for the subset of grants that are not disease-oriented" (Li et al., 2017). Using this rubric of "basicness," the authors observed no association between the "basicness" of research and the likelihood of being cited by a patent. More recently, Long (2019) examined the government contribution to Orange Book patents associated with 300 top-selling drugs from 2013-2017, finding that only $2.6 \%$ of patents included a "government-interest" statement, and that $8.6 \%$ of drugs had at least one patent with a "government-interest" statement.

\footnotetext{
${ }^{7}$ The FDA publishes a list of approved drug products known as the Orange Book in accordance with the HatchWaxman Amendments (1984). The Orange Book "identifies products that have qualified under the FD\&C Act for periods of exclusivity and provides patent information concerning the approved drug products" (https://www.fda.gov/drugs/development-approval-process-drugs/orange-book-preface). The patents listed in the Orange Book represent only those identified by the FDA as being related to the market exclusivity of the product and is not representative of all patents related to the discovery or development of the drug. Patents are only listed in the Orange Book as long as they provide marketing exclusivity, and are eliminated from the database after patent term expiration or successful legal challenge. The complete historical record of patents was obtained from DrugPatentWatch (https://www.drugpatentwatch.com/) and data through 2016 was obtained from Dr. Heidi Williams (http://data.nber.org/fda/orange-book/historical/1986-2016/).
} 


\section{Research Results and Discussion}

Drugs approved by the FDA 2010-2019

We identified new drugs approved by the FDA from 2010 through 2019 by the Center for Drug

Evaluation and Research

(CDER) or the Center for

Biologics Evaluation and

Research $(\mathrm{CBER})^{8}$ (Figure

3). This study excluded

diagnostic products,

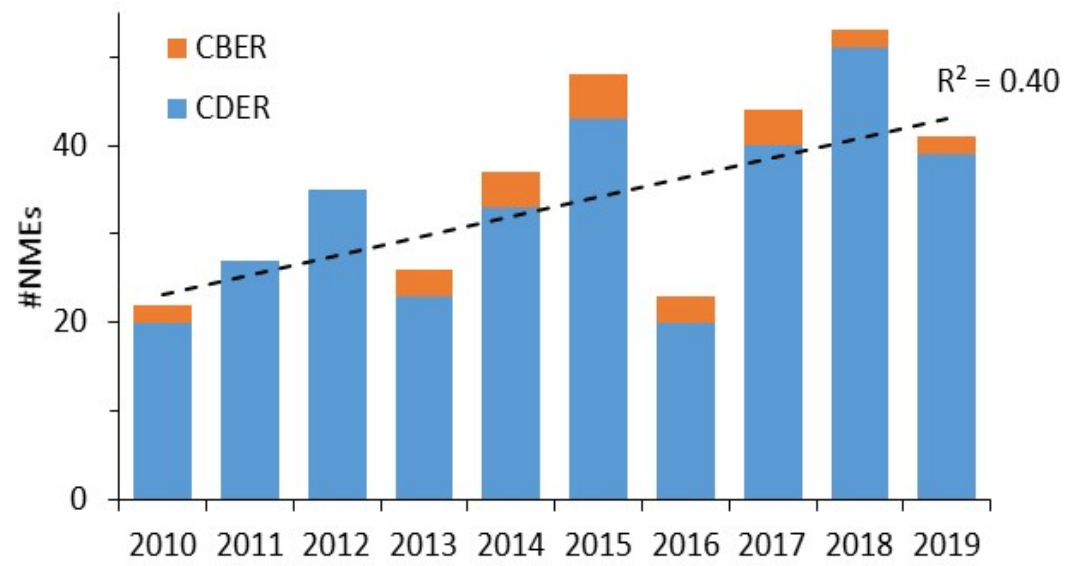

products derived from blood Figure 3. Annual FDA approvals, 2010-2019.

or tissue, and vaccines.

A total of 356 new drugs termed NMEs were approved from 2010-2019, of which 331 were

approved by CDER and 25 approved by CBER over this interval (Table 1). Despite year-to-year

variation, ${ }^{9}$ there was a significant increase in approvals over the 10 -year period (Chi-squared,

\footnotetext{
${ }^{8}$ The FDA approves drugs through two statutory mechanisms. The Center for Drug Evaluation and Research is authorized by the Federal Food, Drug, and Cosmetic Act, and regulates small molecules and many recombinant, biological products that can be well-characterized. The Center for Biologics Evaluation and Research is authorized under the Public Health Service Act, while also subject to the Federal Food, Drug and Cosmetic Act, and regulates biological and blood products defined by their manufacture. New drug classes regulated by CBER include gene therapies, cell and tissue products, vaccines, products for xenotransplantation, and vaccines.

${ }^{9}$ The FDA accounted for the low number of approvals in 2016 as an anomaly resulting from the early, expedited approvals of five drugs in 2015 that originally had PDUFA dates in 2016 (FDA. 2016 Novel Drugs Summary January 2017) (www.fda.gov/downloads/Drugs/DevelopmentApprovalProcess/DrugInnovation/UCM536693.pdf). The Prescription Drug User Fee Amendments (PDUFA) authorizes the FDA to collect user fees from pharmaceutical companies in exchange for a determined timeline for reviewing applications for drug approval (https://www.fda.gov/industry/fda-user-fee-programs/prescription-drug-user-fee-amendments).
} 
Table 1. Product class and FDA expedited drug status of New Molecular Entities (NMEs) approved by the FDA from 2010-2019

\begin{tabular}{|c|c|c|c|}
\hline & Total NME & CDER $^{1}$ & CBER $^{2}$ \\
\hline All & 356 & 331 & 25 \\
\hline \multicolumn{4}{|l|}{ Product class } \\
\hline Phenotypic & 91 & 91 & $\mathrm{n} / \mathrm{a}^{3}$ \\
\hline Targeted & 265 & 240 & 25 \\
\hline Biologic & 126 & 101 & 25 \\
\hline NCE & 230 & 230 & $\mathrm{n} / \mathrm{a}^{4}$ \\
\hline First-in-class & 136 & 136 & $\mathrm{n} / \mathrm{a}$ \\
\hline Orphan drug & 151 & 146 & 5 \\
\hline \multicolumn{4}{|l|}{ Expedited designation (CDER) ${ }^{5}$} \\
\hline Accelerated approval & 46 & 46 & $\mathrm{n} / \mathrm{a}$ \\
\hline Breakthrough therapy & 73 & 73 & $\mathrm{n} / \mathrm{a}$ \\
\hline Fast track & 123 & 123 & $\mathrm{n} / \mathrm{a}$ \\
\hline Priority & 181 & 181 & $\mathrm{n} / \mathrm{a}$ \\
\hline
\end{tabular}

(1) Center for Drug Evaluation and Research (CDER); (2) Center for Biologics Evaluation and Research; (3) All biological products are treated as "targeted" therapeutics; (4) All New Chemical Entities (NCEs) are regulated by CDER; (5) Expedited tracks for approval are only available through CDER. n/a - not applicable

$\mathrm{p}<0.0001$ ) (Figure 3). New drugs were classified as New Chemical Entities (NCEs) or biological products.

An NCE is a drug product comprising a small molecule that can be produced by chemical synthesis. These products are regulated by CDER and represent the majority of all drug products.

A biologic is a drug product comprising a complex molecular structure or cell, typically manufactured by production in a living system such as an animal, plant cell, or microorganism. Biologics can be regulated by either CDER or CBER.

Drug approvals were also categorized by their method of discovery as either phenotypic or targeted (Table 1). Targeted discovery begins with characterizing the structure and function of a biological molecule, usually a protein, with known functions in disease or health, and then 
developing a molecular entity that attaches to that target and alters its function. Our definition of targeted therapeutics also includes recombinant copies or analogs of naturally occurring biological proteins as well as monoclonal antibodies (mAbs) against a specific biological protein. Of the 356 NMEs, 265 (74\%) were classified as targeted.

In contrast, phenotypic discovery begins with an observation of biological changes in living systems, commonly plants or microorganisms, and the subsequent isolation of the molecular entities involved in that change. Such approaches do not rely on knowledge about the structure or function of any specific drug target or its role in disease (Moffat et al., 2017). Of the 356 NMEs, $91(26 \%)$ were classified as phenotypic.

The therapeutic area for each product was determined from the FDA labeled indication and the Anatomical Therapeutic Chemical (ATC) Classification System (Nahler, 2009) and shown for both the 2010-2016 dataset (Cleary et al., 2018) and products approved 2017-19 (Figure 4).

Antineoplastic drugs

constituted the greatest

fraction of approvals (29\%)

for the full decade, followed

by central nervous system

(CNS) and cardiovascular.

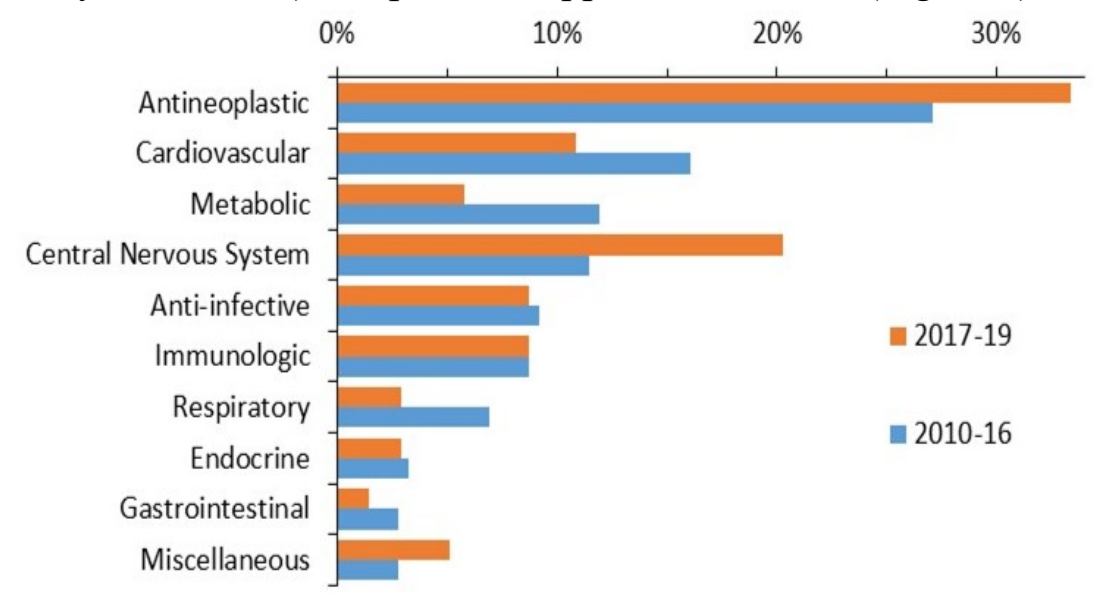

The relative number of

Figure 4. Percentage of NMEs in different therapeutic areas approved from 2010-2016 or 2017-2019.

products varied from 2010

2016 and 2017-2019, with cardiovascular being the second most prevalent therapeutic class from 2010-2016 followed by metabolic, but the fraction of both dropping commensurate with increases in CNS after 2017. 
We identified the start date for each phase of clinical development from PharmaProjects or

Clinicaltrials.gov. We then calculated the time from the initiation of each clinical trial phase to

first product approval (Figure 5). Data were obtained for 188 products entering Phase 1, 256

products entering Phase 2, and 348 products entering Phase $3 .{ }^{10}$ The median length of time from

Phase 1 to approval was 8

years, the median length of

time from Phase 2 to

approval was 7 years, and

the median length of time

from Phase 3 to approval

was 4 years. These values

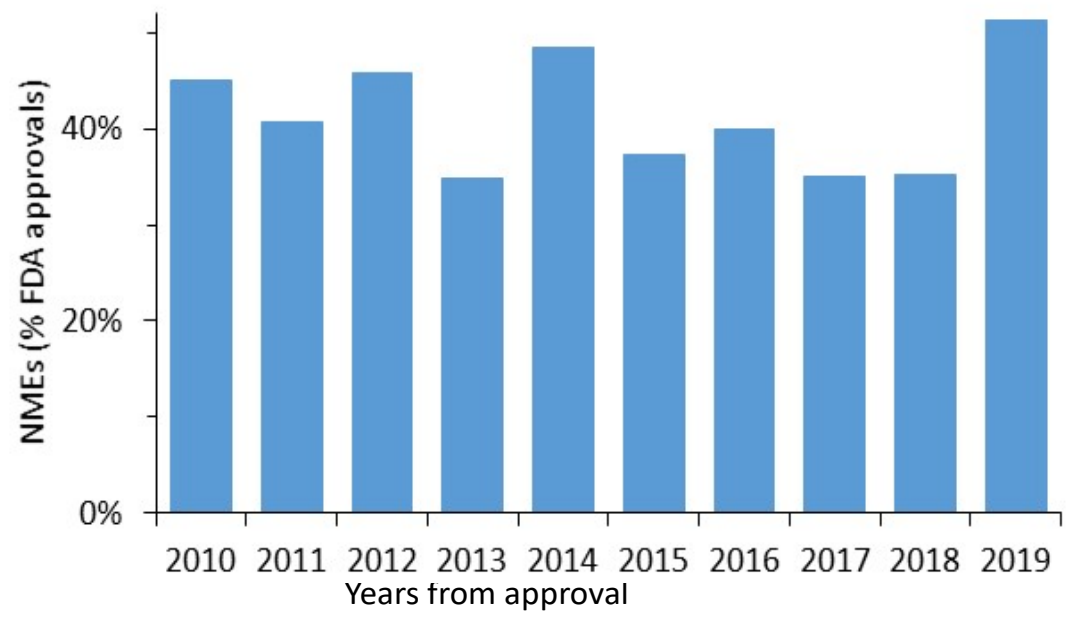

Figure 5. Percentage of NMEs categorized as first-in-class, 2010-2019.

are consistent with the

lengths of clinical trials reported by others (DiMasi et al., 2016; Martin, Hutchens, \& Hawkins, 2017; McNamee, Walsh, \& Ledley, 2017; Wong, Siah, \& Lo, 2019).

\section{Measures of innovativeness}

There are no generally accepted metrics for judging the innovativeness or importance of novel biopharmaceutical products (Kesselheim et al., 2015). To assess innovativeness, products were classified by several different indicators including whether the product was categorized as first-

\footnotetext{
${ }^{10}$ The PharmaProjects database is restricted to publicly available information on the start of clinical trials. Phase 1 and Phase 2 trials in large companies are often not considered material, and are not publicly reported. In 2007, the FDA Amendments Act (FAAA801 (https://www.govinfo.gov/content/pkg/PLAW-110publ85/pdf/PLAW110pub185.pdf\#page=82) created a statutory requirement for reporting information on clinical trials to a "clinical trial registry data bank," ClinicalTrials.gov (https://clinicaltrials.gov/ct2/manage-recs/fdaaa). Compliance with this requirement remains incomplete (DeVito, Bacon, \& Goldacre, 2020). This study used only Phase 1 and Phase 2 dates available from PharmaProjects, but identified Phase 3 start dates missing from PharmaProjects in ClinicalTrials.gov. Drugs without Phase 3 start dates in either database were confirmed to have been approved after a pivotal Phase 2 trial.
} 
in-class and whether it was designated for expedited review. First-in-class drugs were categorized using the method of Lanthier et al. (Lanthier et al., 2013; Miller \& Lanthier, 2015) as reported in CDER annual reviews of new drug approvals. CBER does not provide this categorization. This method categorizes a new drug as first-in-class if it is "pharmacologically innovative because each represents a new pathway for treating a disease.” This categorization explicitly includes the first drug approval related to a novel biological target, and can also include certain novel mechanisms of action on that target. For example, drugs that are selective agonists (stimulators), antagonists (inhibitors) or that bind to a different physical region on the target protein may all be considered first-in-class drugs for that target. This categorization excludes products that may offer major advances in treatment over products using the same pathway, termed "advance-in-class," as well as products that represent an addition-to-class, even though such products may reduce cost, reduce adverse events, improved dosing (compliance), or uniquely benefit subsets of patients. Of the 331 new drugs in our study approved by CDER from 2010-2019, 136 (41\%) were categorized as first-in-class. The percentage of first-in-class drugs varied from $35-51 \%$ with no significant trend through the decade (Figure 6). The fraction of first-in-class drugs in this decade was similar to historical averages, and was higher than the late 1990s and early 2000s, when the apparent paucity of first-in-class drugs attracted considerable attention (Grabowski \& Wang, 2006; Lanthier et al., 2013). 
CDER has four expedited approval tracks ${ }^{11}$ termed Fast Track, Breakthrough Therapy, Accelerated Approval, and Priority Review, each intended to accelerate the development and review process for drugs deemed to treat serious diseases (Darrow, Avorn, \& Kesselheim, 2020; Hwang, Darrow, \& Kesselheim, 2017; Kesselheim et al., 2015). Both CDER and CBER products can also be designated as Orphan Products.

Of the 331 CDER approvals from 2010-19, 46 (14\%) were designated for Accelerated Approval, $73(22 \%)$ as Breakthrough Therapies, 123 (37\%) as Fast Track, and 181 (55\%) for Priority Review (Table 1). Overall, 198 drugs (76\%) had at least 1 expedited designation, with an average of 1.28 designations per drug over the 10-year period (Table 3 ). Both the number of products and percentage of annual approvals having at least one expedited designation increased significantly over the decade (Figure 7A) as did the average number of expedited designations per approval (Figure 7B). These totals and trends are consistent with those described by others (Hwang et al., 2017; Kesselheim et al., 2015; Vadola et al., 2017). Orphan drug designation is granted to products designed to treat a rare disease or condition, or a subset of a disease or condition, affecting less than 200,000 people in the United States ${ }^{12}$ (Boat \& Field, 2011). The designation provides for treatment use of investigational drugs, a facilitated approval process, tax credits, and an extended period of exclusivity and applies to both CBER and CDER products.

\footnotetext{
${ }^{11}$ Expedited approval tracks (definitions quoted from: https://www.fda.gov/patients/learn-about-drug-and-deviceapprovals/fast-track-breakthrough-therapy-accelerated-approval-priority-review): Fast track - a process designed to facilitate the development, and expedite the review of drugs to treat serious conditions and fill an unmet medical need; Breakthrough Therapy - a process designed to expedite the development and review of drugs which may demonstrate substantial improvement over available therapy; Accelerated Approval - these regulations allowed drugs for serious conditions that filled an unmet medical need to be approved based on a surrogate endpoint; Priority Review - Priority Review designation means FDA's goal is to take action on an application within 6 months.

12 The Orphan Drug Designation is described in CFR Title 21 PART 316 https://www.ecfr.gov/cgibin/retrieveECFR $\mathrm{gp}=\& \mathrm{SID}=718 \mathrm{f} 6 \mathrm{fcbc} 20 \mathrm{f} 2755 \mathrm{bd} 1 \mathrm{f5a} 980 \mathrm{eb} 5 \mathrm{eecd} \& \mathrm{mc}=$ true $\& \mathrm{n}=\mathrm{sp} 21.5 .316 . \mathrm{c} \& \mathrm{r}=\mathrm{SUBPART} \& \mathrm{ty}=$ HTML\#se21.5.316 120.
} 
From 2010-19 approval period, 146 (44\%) of CDER approvals were granted orphan status and 5 (25\%) for CBER.

The significance of expedited designations as a proxy for innovativeness is unclear. Drugs receiving at least one expedited designation have been reported to provide greater health benefits than other products (Chambers et al., 2017). There is growing concern, however, that the reduced clinical trials may lead to product approvals on the basis of incomplete results that are not confirmed by more robust, follow-on studies (Darrow, Avorn, \& Kesselheim, 2014), that the
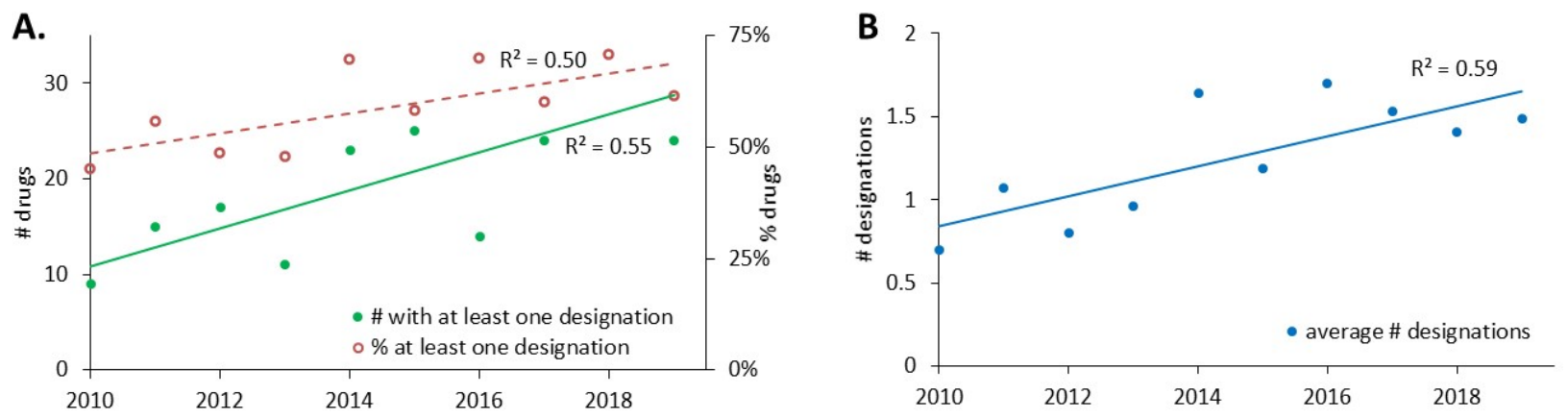

Figure 7. Expedited approval designations for new drugs approved 2010-2019. A. Drugs with at least one expedited approval designation. B. Average number of expedited approval designations.

clinical impact of products approved on the basis of surrogate end points may prove to have only limited clinical impact (Gyawali, Hey, \& Kesselheim, 2019); that data on drug safety may not be complete (Mostaghim, Gagne, \& Kesselheim, 2017); or that confirmatory trials may not be completed or are completed only years after the products are on the market (Beaver et al., 2018; Naci, Smalley, \& Kesselheim, 2017; Woloshin et al., 2017).

\section{Modeling technology maturation}

As described briefly in Section 1, Introduction, the TIME model assesses the maturation of biomedical research on specific topics and the readiness of this technology to support successful drug development. Specifically, it calculates a point of technology initiation (Ti), which is 
commonly associated with a seminal insight or invention that gives rise to a new area of inquiry, and a point the technology is established (Te), which previous studies have shown generally precedes first approval of a new drug based on that research (Figure 2).

We modeled the maturation of research on the biological targets of new drugs approved from 2010-2019. For each new drug, or NME, the biological target was identified from the FDA label and confirmed from PharmaProjects or literature review. For "targeted" therapeutics, the target was the protein or its function used to discover the new drug. For "phenotypic" therapeutics, the target was the protein or its function most commonly associated with the drug's activity. For biologics other than monoclonal antibodies, the biological target was the entity comprising, or analogous to, the NME. For example, for insulin analogs, insulin is treated as the "target." We then searched PubMed (Medline) $)^{13}$ using the updated Automatic Term Mapping (May 2020) with Boolean search terms optimized for specificity and breadth by examining publication titles, abstracts, and descriptions of search results for randomly selected result pages and eliminating query terms that introduced irrelevant results. Publications were identified by a PubMed Identifier (PMID) and publication year and all data collected using web data mining in the R programming language.

A total of 219 unique biological targets were identified, associated with 337 drugs. The remaining 19 NMEs could not be associated with a discrete biological target or the target is unknown. Of the 219 targets, research on 159 (73\%) exhibited an exponentiated logistic pattern of technology advance and reasonable fit with the TIME model (exponentiated logistic function). Predictable exceptions included technologies that exhibited an exponential pattern of growth,

${ }^{13}$ PubMed: https://pubmed.ncbi.nlm.nih.gov/, accessed May 12, 2020. 
consistent with an immature technology, and technologies exhibiting complex, multiphasic Scurves, consistent with the observation of technological maturation by successive S-curves (Christensen, 1997; Foster, 1982). Some did not exhibit an exponential growth phase. The 159 technologies successfully modeled were associated with 232 product approvals.

Figure 8 shows the time intervals from Ti and Te to first approval for new drugs approved 20102019 for which data were available. Table 2 shows the median intervals from Ti, Te, Phase 1 start, Phase 2 start, and Phase 3 start for products approved 2010-2019 and different subsets of these products.

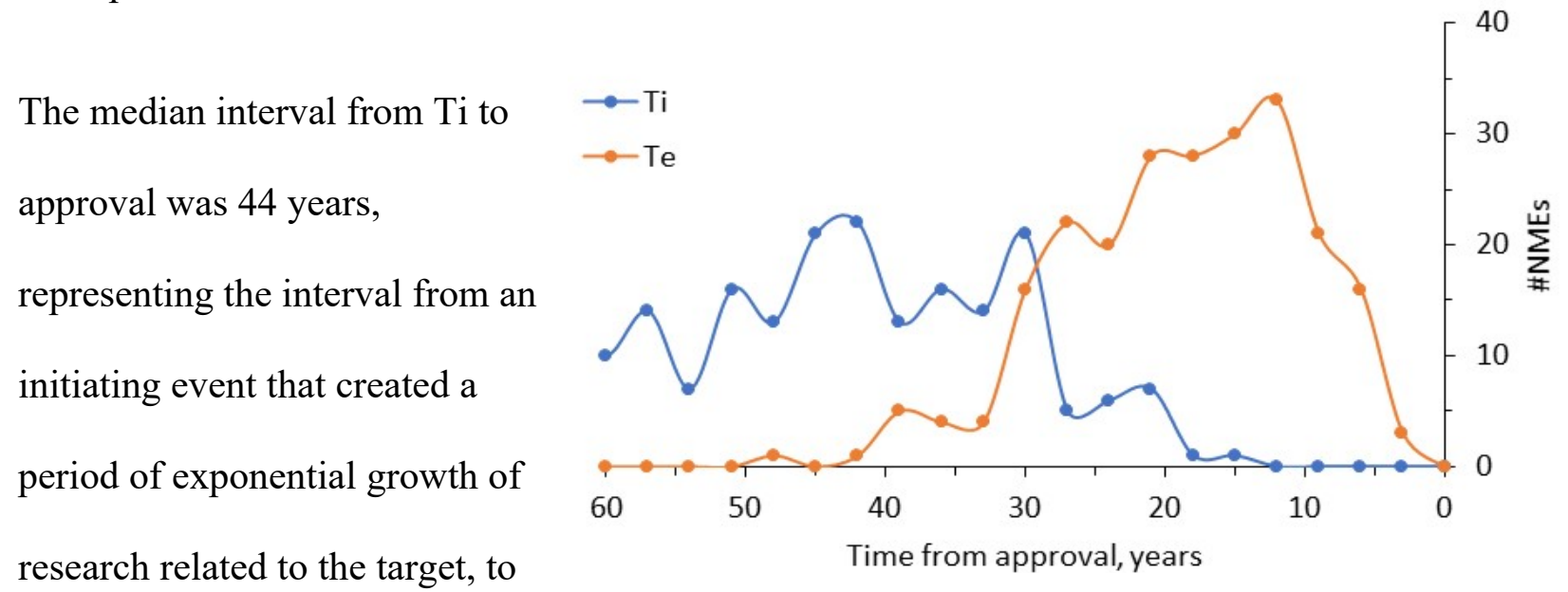
approval of a drug associated Figure 8. Time from technology initiation (Ti) or technology established (Te) points to first approval, 2010-2019.

with that target. This initiating event often does not involve the actual discovery or characterization of the target, but rather research on the targets or 
Table 2. Years from R\&D milestones to approval for NMEs approved 2010-2019.

\begin{tabular}{|c|c|c|c|c|c|c|c|c|c|c|}
\hline \multirow[b]{2}{*}{$\begin{array}{l}\text { Subset of drugs approved } \\
2010-2019 \\
\end{array}$} & \multicolumn{2}{|c|}{$\begin{array}{l}\text { Initiation point } \\
\text { (Ti) }\end{array}$} & \multicolumn{2}{|c|}{$\begin{array}{c}\text { Established point } \\
\text { (Te) }\end{array}$} & \multicolumn{2}{|c|}{ Phase 1} & \multicolumn{2}{|c|}{ Phase 2} & \multicolumn{2}{|c|}{ Phase 3} \\
\hline & $\mathbf{N}$ & $\begin{array}{l}\text { Median } \\
\text { (yrs) }\end{array}$ & $\mathbf{N}$ & Median (yrs) & $\mathbf{N}$ & $\begin{array}{l}\text { Median } \\
\text { (yrs) }\end{array}$ & $\mathbf{N}$ & Median (yrs) & $\mathbf{N}$ & $\begin{array}{c}\text { Median } \\
\text { (yrs) }\end{array}$ \\
\hline All & 232 & 44 & 232 & 17 & 117 & 9 & 170 & 7 & 226 & 4 \\
\hline \multicolumn{11}{|l|}{ Drug subset } \\
\hline CDER & 227 & 44 & 227 & 17 & 114 & 9 & 168 & 7 & 221 & 4 \\
\hline CBER & 5 & 47 & 5 & 25 & 3 & 7 & 2 & 8 & 5 & 5 \\
\hline Phenotypic & 60 & $58 * *$ & 60 & 19 & 30 & 10 & 43 & 7 & 60 & 5 \\
\hline Targeted & 172 & 43 & 172 & 17 & 87 & 9 & 127 & 7 & 166 & 4 \\
\hline NCE & 161 & 44 & 161 & 17 & 73 & 9 & 113 & 7 & 158 & 4 \\
\hline Biologic & 71 & 43 & 71 & 19 & 44 & 9 & 57 & 7 & 68 & 5 \\
\hline First-in-class & 97 & 44 & 97 & 17 & 58 & 9 & 80 & 7.5 & 93 & 4 \\
\hline Follow-on & 129 & 43 & 129 & 17 & 56 & 9 & 88 & 7 & 127 & 4 \\
\hline Orphan & 91 & 47 & 91 & 18 & 57 & 9 & 71 & 7 & 86 & 4 \\
\hline Other & 136 & 42 & 136 & 15 & 57 & 9 & 97 & 7 & 135 & 4 \\
\hline \multicolumn{11}{|c|}{ Designation for expedited review } \\
\hline Accelerated approval & 24 & 44 & 24 & 17 & 16 & 7.5 & 23 & $6^{*}$ & 23 & $2 * * *$ \\
\hline other & 203 & 44 & 203 & 17 & 98 & 9 & 145 & 8 & 198 & 4 \\
\hline Breakthrough therapy & 41 & 46 & 41 & 18 & 22 & 7.5 & 30 & 6 & 38 & $3 * * *$ \\
\hline other & 172 & 43 & 172 & 17 & 86 & 9 & 129 & 7 & 169 & 5 \\
\hline Fast track & 71 & 43 & 71 & 15 & 39 & 8 & 52 & 7 & 69 & 3 \\
\hline other & 156 & 44 & 156 & 18 & 75 & 9 & 116 & 7 & 152 & 5 \\
\hline Priority & 115 & 45 & 115 & 17 & 71 & 8 & 87 & 7* & 110 & $3.5^{* * *}$ \\
\hline other & 112 & 43 & 112 & 17 & 43 & 9 & 81 & 8 & 111 & 5 \\
\hline
\end{tabular}

Ti and Te data are shown for 232 of 356 drugs approved by the FDA from 2010 to 2019 . Of the other drugs, 19 were phenotypic with no known target/mechanism of action, and 105 exhibited TIME model growth patterns that did not fit the exponentiated logistic model. Phase 1 and Phase 2 start dates shown are those given in PharmaProjects. Phase 3 start dates were from PharmaProjects or ClinicalTrials.gov. Statistical analysis compared associated subcategories, CDER vs. CBER, first-in-class vs. follow-on, phenotypic vs. targeted, NCE vs. biologic, and CDER designations vs. non-designated, using a Mann-Whitney, nonparametric, two independent samples test. With a Bonferroni correction of 9 , a difference with a $p$ value below 0.0056 was considered significant $(p>0.0056, * p \leq 0.0056, * *$ $p \leq 0.0011, * * * p \leq 0.0001)$. 
technologies that led to that discovery (Beierlein, et al., 2017; McNamee, Walsh \& Ledley, 2017). The median interval from Te to approval was 17 years, representing the time from maximum slowing of exponential advances on the drug target to successful approval of a drug based on these advances. Both values are commensurate with those described previously (McNamee, Walsh, \& Ledley, 2017).

The clinical timelines from the initiation of the first Phase 1, Phase 2, or Phase 3 trials to approval is shown in Table 2. The median time from initiation of Phase 1 to approval was 9 years, from initiation of Phase 2 to approval was 7 years, and from initiation of Phase 3 to approval was 4 years. The significance of a mature foundation of basic research and drug approvals is evident in two observations. First, Figure 9A shows that drug approvals lag after the established point of the technology (Te) with a median of 17 years. Moreover, no new drugs in this study were approved before the established point and only 3 within the first three years after this point. This is consistent with previous observations showing that approval of targeted cardiovascular drugs (Beierlein et al., 2017), cancer drugs (McNamee \& Ledley, 2017), and nucleotide therapeutics (Beierlein, McNamee, \& Ledley, 2017) occurred uniformly after the
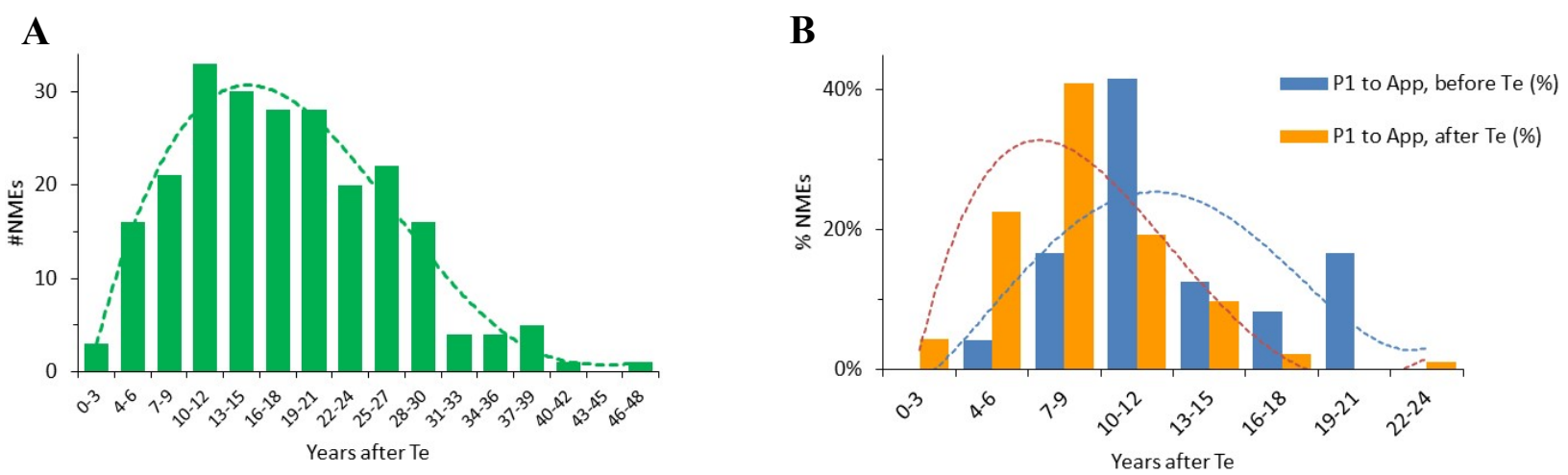

Figure 9. Time of first NME approval after established point (Te) of research on the drug target. A. Time after Te for all NMEs. B. Time after Te for NMEs beginning clinical trials before Te and those beginning clinical trials after Te. Data are shown for 232 NMEs associated with 161 biological targets with exponentiated logistic patterns of maturation enabling estimate of the Te with the TIME model. 
Table 3. Duration of clinical development from Phase 1 to approval for NMEs with trials initiated before the underlying technology passed the established point and after that point.

\begin{tabular}{|c|c|c|c|c|c|c|c|}
\hline \multirow[b]{3}{*}{ Type } & \multicolumn{3}{|c|}{ \# NMEs } & \multicolumn{4}{|c|}{ Year from Phase 1 to approval } \\
\hline & \multicolumn{3}{|c|}{ Initiation of Phase 1 trial } & \multicolumn{4}{|c|}{ Initiation of Phase 1 trial } \\
\hline & all & before Te & after Te & all & before Te & after Te & $\mathbf{p}$ \\
\hline All & 117 & 24 & 93 & 9 & 11 & 8 & $* * *$ \\
\hline \multicolumn{8}{|l|}{ Drug subset } \\
\hline CDER & 114 & 24 & 90 & 9 & 10 & 8 & $* * *$ \\
\hline CBER & 3 & 0 & 3 & 7 & - & 6 & $\mathrm{n} / \mathrm{a}$ \\
\hline Phenotypic & 30 & 8 & 22 & 10 & 10.5 & 9 & ns \\
\hline Targeted & 87 & 16 & 71 & 9 & 9.5 & 8 & $* * *$ \\
\hline NCE & 73 & 16 & 57 & 9 & 9 & 8 & $*$ \\
\hline Biologic & 44 & 8 & 36 & 9 & 10 & 8 & ns \\
\hline First-in-class & 58 & 15 & 43 & 9 & 11 & 7.5 & $* * *$ \\
\hline Follow-on & 56 & 9 & 47 & 9 & 8 & 8 & ns \\
\hline Orphan drug & 57 & 9 & 48 & 9 & 9.5 & 7 & $* * *$ \\
\hline \multicolumn{8}{|l|}{ Expedited designations } \\
\hline Accelerated approval & 16 & 3 & 13 & 7.5 & 5 & 7 & $\mathrm{n} / \mathrm{a}$ \\
\hline Breakthrough therapy & 22 & 1 & 21 & 7.5 & 5 & 6.5 & $\mathrm{n} / \mathrm{a}$ \\
\hline Fast track & 39 & 9 & 30 & 8 & 10 & 7 & $*$ \\
\hline Priority & 71 & 13 & 58 & 8 & 10 & 7 & $* * *$ \\
\hline
\end{tabular}

Data show for 117 of 356 drugs approved by the FDA from 2010 to 2019. Of the absent compounds, 19 were phenotypic with no known target/mechanism of action, and 105 exhibited TIME model growth patterns that did not fit the exponentiated logistic model. Of the remaining 232 accepted TIME model fits, 117 were matched with a Phase 1 clinical trial start date, thus 'Years in clinical trials' could be calculated. Statistical analysis compared the duration of clinical trials (Phase 1 start date to approval date) between NMEs that entered clinical trials before or after the target/technology establishment point (Te) or point of maturity, using the nonparametric, Mann-Whitney $\mathrm{U}$ test. With a Bonferroni correction of 14 , a difference with a $p$ value below 0.0036 was considered significant (ns - not significant, $p>0.0036, * p \leq 0.0036, * * p \leq 0.0007, * * * p \leq 0.00007$ ); n/a - not applicable 
underlying bodies of research passed this threshold, and the suggestion that the persistent lags in developing products for Alzheimer's Disease (Beierlein et al., 2015) and gene therapy (Ledley et al., 2014) could be related to the immaturity of essential, underlying research.

Second, Table 3 compares the timeline for clinical development from Phase 1 to first approval for products that entered clinical development before research on the biological target had reached the established point and those that entered clinical trials after that point. This is illustrated in Figure 9B. These data show that the clinical development timeline is significantly shorter when the underlying research had passed the established point (median 11 years versus 8 years, $\mathrm{p}<0.0001)$.

Table 3 also shows that this association was significant for targeted therapeutics, where development is predicated on a mature body of research, but there was no significant association with drugs discovered using phenotypic methods. Moreover, there was no significant association for biologic products, which are classified as "targeted," but are discovered because of their known biological activities. Together, these results suggest that a mature body of underlying research improves the efficiency of the drug development process and may be requisite for successful product development.

\section{NIH project funding and costs}

As noted in Section 2, the public sector is primarily responsible for funding the basic biomedical foundation that provides the groundwork for drug discovery and development. In the United States, most of this funding comes from the NIH. To assess the NIH's contribution to the research that enabled development of new drugs approved from 2010-2019, we identified NIH funding for published research related to another 219 biological targets described above, as well 
as published research directly related to the 356 drugs themselves. This analysis expanded on the study of new drugs approved from 2010-2016 by Cleary et al. (2018) and employed a modification of that method.

The analysis involved recovering the PMIDs for each research publication identified through the PubMed searches for drug targets described above as well as searches performed individually for each of the 356 drugs in this study. PMIDs were identified for the years 1960 through the year of first FDA approval for each drug. When there were multiple drugs against one target, searches included years before the first drug approval. By restricting this analysis to PMIDs published before drug approval, we minimized the number of publications related to the clinical use or marketing of products after approval. PMIDs from searches for each of the 356 drugs (DRUG search) represented research directly related to the approved product and is considered to be applied or translational research. PMIDs from searches for each of the 219 biological targets (TARGET searches) are indirectly related to the drugs and are considered use-inspired, or basic research. PMIDs identified in both a DRUG search and a TARGET search are classified as being drug related. NIH funding for this published research was identified by associating each PMID with NIH-funded Projects (grants) in the NIH RePORTER database. ${ }^{14}$ NIH RePORTER includes NIH-funded Projects from 1980-present and identifies publications acknowledging grant funding.

For this analysis, each PMID was linked to a specific Funding Year, representing one fiscal year of the project corresponding to the publication date of the PMID. PMID with publication dates

\footnotetext{
${ }^{14}$ The NIH Research Portfolio Online Reporting Tool (RePORT) was created by the Office of Extramural Research at the NIH in 2008 as a repository for information on research funding from the NIH. This data resource includes NIH RePORTER (RePORT Expenditures and Results), which includes data on NIH Projects (grants) as well as publications (PMID citations) and Patents acknowledging support from these grants (https://report.nih.gov/index.aspx).
} 
1-4 years after the final year of Project funding were considered to be associated with the final fiscal year of Project funding to account for the observed lags between research funding and publication (Boyack \& Jordan, 2011). Data cleaning was performed to eliminate duplicate entries and exclude publications occurring before the first year of Project funding or more than four years after the last fiscal year of funding. Project Costs for each project Funding Year identified in this analysis were derived from the RePORTER database, which has Costs from 2000present.

Table 4. Research publications, NIH Funding Years, and Project Costs associated with 356 NMEs approved by the FDA from 2010-2019 or their molecular targets

\begin{tabular}{|c|c|c|c|}
\hline & \multicolumn{3}{|c|}{ TARGET } \\
\hline & DRUG Search & Search & Total \\
\hline \multicolumn{4}{|l|}{ PubMed search results } \\
\hline Searches & 356 & 219 & 574 \\
\hline Unique publications in PubMed (1980-2019) & 244,327 & $1,977,678$ & $2,222,005$ \\
\hline \multicolumn{4}{|l|}{ RePORTER Link table results } \\
\hline \multicolumn{4}{|l|}{ Unique publications with NIH funding (1980- } \\
\hline 2019) & 39,099 & 424,192 & 463,291 \\
\hline \% publications with NIH funding & $(16 \%)$ & $(21.4 \%)$ & $(21 \%)$ \\
\hline \multicolumn{4}{|l|}{ Totals } \\
\hline Searches with NIH funding & 310 & 219 & $\mathrm{n} / \mathrm{a}$ \\
\hline Fraction of searches with NIH funding & $(87 \%)$ & $(100 \%)$ & $\mathrm{n} / \mathrm{a}$ \\
\hline Funding Years and Costs & DRUG & TARGET only & Total \\
\hline Unique Funding Years & 63,687 & 515,179 & 578,866 \\
\hline \multicolumn{4}{|l|}{ Number of Funding Years with Costs in } \\
\hline RePORTER & 32,972 & 299,052 & 332,024 \\
\hline Program Costs, \$ millions (\% total) & $\$ 35,687(15 \%)$ & $\begin{array}{c}\$ 194,919 \\
(85 \%)\end{array}$ & $\$ 230,606$ \\
\hline
\end{tabular}

Table 4 shows the number of research publications, NIH Funding Years, and Project Costs associated with this set of approvals, while Figure 10 illustrates the time course of PMIDs, NIH- 
funded PMIDs, NIH funding years, and Project Costs associated with the 356 NMEs or their molecular $\operatorname{targets}^{15}$. DRUG searches identified more than 460,000 publications, while TARGET searches identified over 3 million publications. Of these, approximately 40,000 PMIDs (16\%) identified in DRUG searches had NIH funding in the RePORTER database, while more than 420,000 (21\%) of PMIDs identified in TARGET searches had NIH funding in the RePORTER database. NIH funding for publications identified in this work comprised more than 575,000 fiscal years of Project Funding (more than 60,000 fiscal years of research related to the drugs and greater than 515,000 fiscal years of research related to the drug targets). In all, NIH funding was identified for research directly associated with 87\% of all the drugs approved from 2010-2019 and $100 \%$ of the known biological targets for these drugs (Table 4). In comparison, in our previous work examining new drugs approved 2010-2016, (Cleary et al., 2018) identified NIH funding was associated with $94 \%$ of all DRUG searches, likely due to the inclusion of publications dated after drug approval in the earlier study. Importantly, NIH-funded research was associated with every one of the 356 drugs or their biological targets.

This work identified a total of $\$ 230.6 \mathrm{~B}$ in NIH funding directly or indirectly related to the drugs approved from 2010-2019. Of this amount, \$35.7B (15\%) was associated with research identified through DRUG searches, which is considered to be applied research, while $\$ 194.9 \mathrm{~B}$ $(85 \%)$ was associated with research identified only through TARGET searches, which is considered to represent basic research.

\footnotetext{
${ }^{15}$ Note: the apparent decrease in PMIDs, Funding Years, and Project Costs after 2010 reflects the experimental design in which PMIDs with publication dates after first drug approval were not included in the analysis. Thus, the number of drugs and target searches included in the analysis decreases each year after 2010.
} 

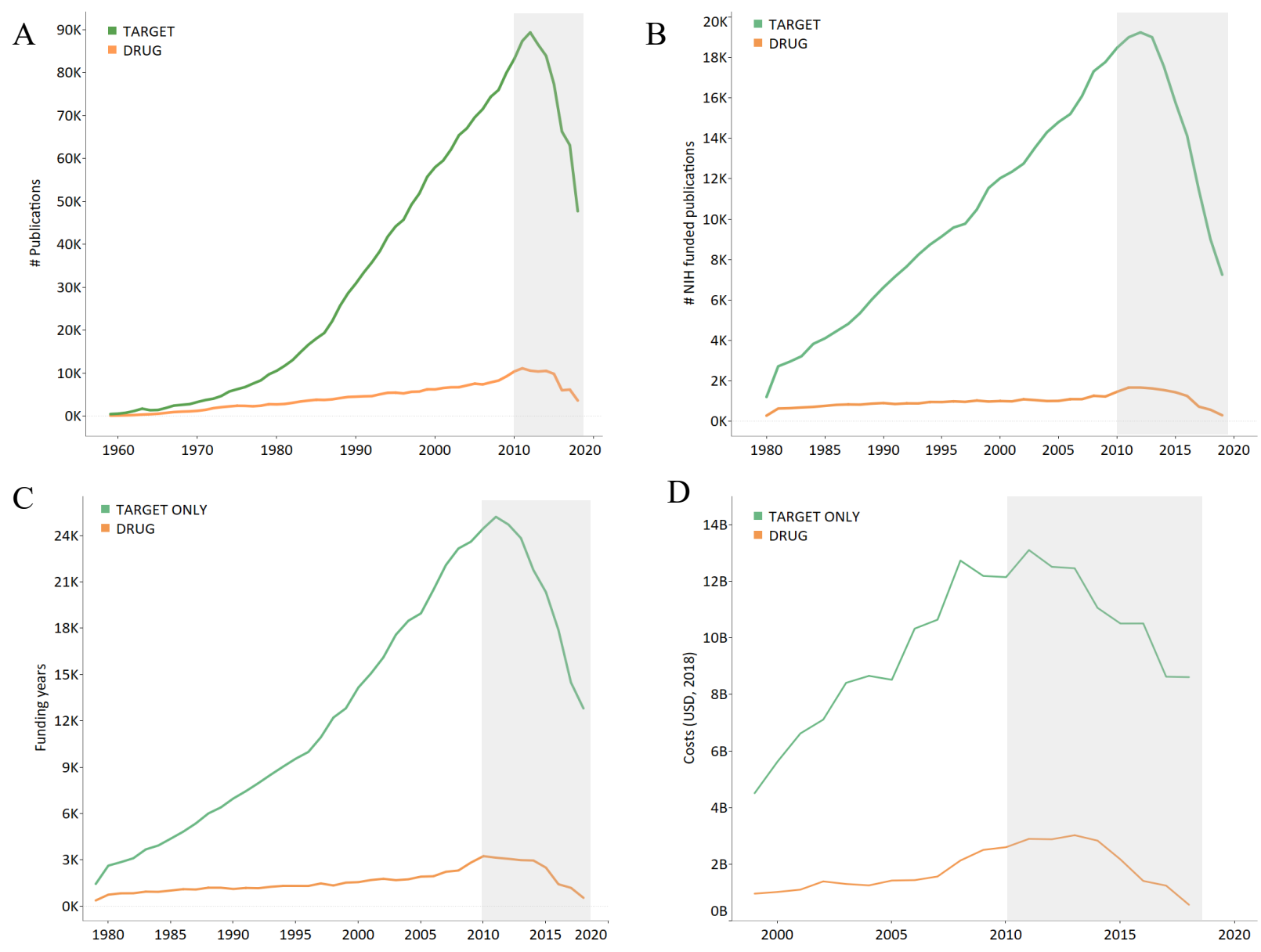

Figure 10. Number of PMIDs, NIH-funded PMID, NIH Funding Years, and project Costs associated with research on 356 NMEs approved 2010-2019 or their biological targets. PubMed Searches were performed for 356 NMEs (DRUG search) or their known biological targets (TARGET search). A. Publications in PubMed (PMID) (1960-2019); B. PMIDs associated with NIH-funding in NIH RePORTER (1980-2019); C. Funding Years associated with NIH-funded PMIDs (1980-2019). Funding Years correspond to the fiscal year of funding corresponding to the year of publication or the last year of publication for PMIDs published 1-4 years after the last year of the grant; D. Project Costs (2000-2019). Note: the decrease in PMIDs, Funding Years, and Costs after 2010 is due to the experimental method, which considered only PMIDs published before the date of first drug approval.

\section{NIH investment in first-in-class drugs}

To assess the amount of NIH funding that goes into research on a novel drug target before approval of the first-in-class drug associated with that target, we examined the funding for research related to the 136 first-in-class products in this dataset and their biological targets. 
Table 5. Funding Years and NIH Costs associated with 136 first-in-class products.

\begin{tabular}{|c|c|c|c|c|}
\hline & $\mathbf{N}$ & DRUG & TARGET only & TOTAL \\
\hline \multicolumn{5}{|l|}{ Funding Years } \\
\hline All & 136 & 27,634 & 415,470 & 443,104 \\
\hline Targeted & 101 & 21,876 & 286,363 & 308,239 \\
\hline Phenotypic & 35 & 5,758 & 129,107 & 134,865 \\
\hline \multicolumn{5}{|l|}{ Costs } \\
\hline All & 136 & $\$ 16,660 \mathrm{M}$ & $\$ 175,135 \mathrm{M}$ & $\$ 191,795 \mathrm{M}$ \\
\hline Targeted & 101 & $\$ 13,006 \mathrm{M}$ & $\$ 128,974 \mathrm{M}$ & $\$ 141,980 \mathrm{M}$ \\
\hline Phenotypic & 35 & $\$ 3,654 \mathrm{M}$ & $\$ 46,162 \mathrm{M}$ & $\$ 49,815 \mathrm{M}$ \\
\hline Costs/NME & & $\$ 122 \mathrm{M}$ & $\$ 1,288 \mathrm{M}$ & $\$ 1,410 M$ \\
\hline
\end{tabular}

Of these, 84 were first discovered through targeted discovery and 32 by phenotypic discovery. Of these, the NIH contributed funding for research related to each of the 136 first-in-class drugs and each of the biological targets. NIH investment associated with these products totaled more than 440,000 fiscal years of grant funding and more than $\$ 190$ billion dollars, which is an average of $\$ 1.4$ billion dollars per first-in-class drug (Table 5). ${ }^{16}$

\section{NIH investment by therapeutic area}

The NIH investment in drugs for diseases in different therapeutic areas is shown in Table 6. The number of new drugs and NIH Costs was highest for antineoplastic agents. Overall, the number of NMEs in each therapeutic class is strongly correlated with the total NIH spending $\left(\mathrm{R}^{2}=.89\right.$,

\footnotetext{
${ }^{16}$ Note: this reflects the total amount of research directly or indirectly related to each first-in-class drug launch. In this analysis, a Project Cost that was related to more than one approved drug would be counted with each product, and therefore counted more than once in calculating total values.
} 
$\mathrm{p}<0.0001$ ), but there are notable deviations. While the second largest category of drug approvals was for cardiovascular disease, total NIH spending was larger for anti-infectives, CNS and

Table 6. Funding years and Costs associated with published research for NMEs approved 20102019 by therapeutic area.

\begin{tabular}{rcccc}
\hline Therapeutic area & $\begin{array}{c}\text { NIH-funded } \\
\text { NMEs }\end{array}$ & $\begin{array}{c}\text { DRUG Costs } \\
\text { (Funding Years) }\end{array}$ & $\begin{array}{c}\text { TARGET ONLY Costs } \\
\text { (Funding Years) }\end{array}$ & $\begin{array}{c}\text { TOTAL Costs } \\
\text { (Funding Years) }\end{array}$ \\
\hline antineoplastic & 100 & $\$ 10,629(9270)$ & $\$ 108,407(198436)$ & $\$ 119,036$ \\
anti-infective & 30 & $\$ 1,684(873)$ & $\$ 61,364(86852)$ & $\$ 63,048$ \\
central nervous system & 37 & $\$ 1,758(2130)$ & $\$ 48,516(92045)$ & $\$ 50,274$ \\
immunologic & 27 & $\$ 2,008(1541)$ & $\$ 42,407(64074)$ & $\$ 44,416$ \\
cardiovascular & 47 & $\$ 16,639(20817)$ & $\$ 18,708(30356)$ & $\$ 35,347$ \\
endocrine & 8 & $\$ 5,580(5497)$ & $\$ 23,428(37311)$ & $\$ 29,008$ \\
metabolic & 31 & $\$ 2,637(2370)$ & $\$ 18,360(25938)$ & $\$ 20,996$ \\
miscellaneous & 9 & $\$ 161(134)$ & $\$ 17,720(29821)$ & $\$ 17,881$ \\
respiratory & 14 & $\$ 1,888(1423)$ & $\$ 9,931(16812)$ & $\$ 11,820$ \\
gastrointestinal & 7 & $\$ 32(43)$ & $\$ 11,177(21324)$ & $\$ 11,209$ \\
\hline
\end{tabular}

All costs since 2000 in millions USD.

immunological disorders. Similarly, while the second largest category of total spending was for anti-infectives, there were more agents approved for cardiovascular, CNS, and metabolic diseases. There was no significant correlation between NIH spending for TARGET and DRUG research $\left(\mathrm{R}^{2}=.22\right.$, NS). The most notable outlier was cardiovascular disease, which had the largest amount of NIH spending related to DRUGs but ranked sixth in spending on TARGETs.

\section{Research activities funded by the $\mathrm{NIH}$}

To assess the types of research activities, we examined the Activity Codes of the NIH Projects identified as being directly or indirectly associated with these 356 drug approvals. NIH not only funds traditional, investigator-initiated Research Projects, typified by classic "RO1 funding," but also funding targeted for small projects (R21), and first-time investigators (R29), and other 
specific projects. Each activity is indicated by a unique three-digit Activity Code, with the first letter indicating the Activity category. ${ }^{17}$ The NIH also provides funding for Program Project and Center grants, which support research capacity at large research centers, where efficiencies are created by sharing expensive facilities, equipment, and personnel for animal experimentation, analytical chemistry, advanced instruments, large scale production, bioinformatics, and other common research infrastructure needs. Each grant can contribute to the fully allocated cost of research on many different projects. Cooperative Agreements are government-initiated research projects, which often include substantial federal programmatic involvement including government coordination, personnel, or facilities. Other types of NIH funding provide support for graduate students or research fellows, promote diversity in science education or research, or provide career support for accomplished scientists. Such grants provide salary for many of the scientists involved in Research Programs, Program Projects, Centers, or Cooperative Programs, and can contribute to fully allocated cost of research on many different projects. The NIH also supports the research of government scientists at the NIH through Intramural Programs. Figure 11 shows that Funding years and Project Costs categorized by the first letter of the Activity Code. Research Projects (e.g., R01, R21, R29) constituted the greatest number of both Funding Years (66\%) and Project Costs (39\%) followed by Research Program Projects and Centers (e.g., P30, P50), and Cooperative Agreements (e.g., U01, U09). While the number of Program Projects and Centers and Cooperative Agreements represent a small fraction of the Funding Years identified in this study ( $8 \%$ and $6 \%$ respectively), they comprise a disproportionately large fraction of the total Costs ( $24 \%$ and $21 \%$ respectively). Several different forms of funding for

\footnotetext{
${ }^{17}$ NIH grants are categorized by the first letter of the Activity Code. Activity Codes are: R, Research Projects; P, Research Program Projects and Centers; U, Cooperative Agreements; K, Research Career Programs; Z, Intramural Research; T, Training Programs; D, Training Projects; F, Fellowship Programs; M, General Clinical Research Centers Programs (discontinued 2014). https://ods.od.nih.gov/research/CARDS lists.aspx.
} 

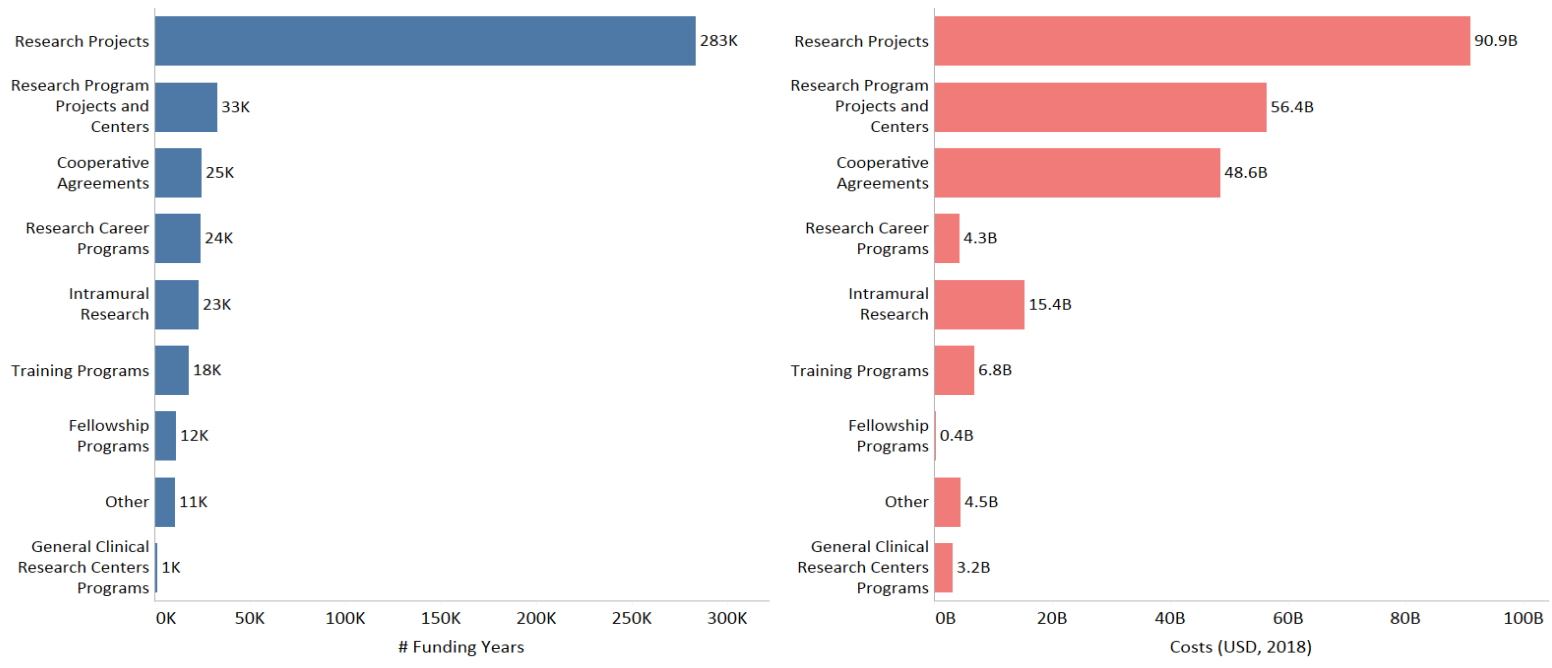

Figure 11. Funding Years (left panel) and Project Costs (right panel) associated with different forms of NIH funding since 2000 .

training and fellowships contributed smaller fractions of total NIH funding. This analysis suggests that the NIH contribution to drug development does not simply involve funding for investigator-initiated research programs, but also funding for a complex infrastructure of capabilities and personnel required to conduct research. It should be noted that contracts are not included in the RePORTER database, nor are many other NIH contributions to research infrastructure, including construction.

\section{NIH-funded patents associated with approved drugs}

Patents were identified in RePORTER associated with NIH Projects that also cited PMIDs identified in DRUG or TARGET searches from 1980-2019. We identified 22,409 such patents representing 17,564 patent families (Table 7). The time course of patent issuance dates is shown in Figure 12. The earliest patents identified in this study were from 1980. The number of patents increased rapidly after 1995, peaking between 1999-2002, then dropping until 2010 when the number increased again. The leveling of the number of patents and decrease over the past two 
years is likely due to the experimental method, which only looks at the funding for research published before drug approval and the patents arising from this funding.

Table 7. Identification of NMEs approved 2010-2019 with patents in the Orange Book funded by NIH-funded Projects also supporting published research on the NMEs or their biological targets.

\begin{tabular}{|c|c|c|c|}
\hline Category & $\begin{array}{l}\text { Patents } \\
\qquad \mathbf{N}\end{array}$ & $\begin{array}{c}\text { Patent } \\
\text { families } \\
\mathbf{N}\end{array}$ & $\begin{array}{c}\text { NME } \\
\text { (brand) } \\
\mathbf{N}\end{array}$ \\
\hline Patent-IND combinations in the Orange Book (all years) ${ }^{1}$ & 49,154 & $\mathrm{n} / \mathrm{a}$ & 2,415 \\
\hline Patents in the Orange Book (all years) ${ }^{1}$ & 26,579 & $\mathrm{n} / \mathrm{a}$ & 2,415 \\
\hline Patents with NIH funding related to NMEs 2010-2019 2 & 22,409 & 17,564 & $\mathrm{n} / \mathrm{a}$ \\
\hline Patent-IND combinations in the Orange Book ${ }^{3}$ & 1,204 & $\mathrm{n} / \mathrm{a}$ & $\mathrm{n} / \mathrm{a}$ \\
\hline Patents in the Orange Book ${ }^{3}$ & 567 & 487 & 144 \\
\hline NME associated with patents in the Orange Book ${ }^{4}$ & $\mathrm{tbc}$ & tbc & 27 \\
\hline
\end{tabular}

(1) Archival data of active and inactive patents from DrugPatentWatch; (2) patents associated with $\mathrm{NIH}$-funded Projects acknowledged in publications on the NME (DRUG) or biological target (TARGET). Many do not include patents from other NIH Projects; (3) includes patents funded by NIH Projects as described in table footnote 2. (4) includes new drugs approved 2010-2019 with patents identified in table footnote \#3. n/a - data not available from current datasets; tbc - data to be calculated; Identities between the Orange Book confirmed by matching brand/trade names.

Of these patents, 567 were included in the Orange Book, representing 487 patent families. These patents were associated with 144 different products in the Orange Book (1980-present)

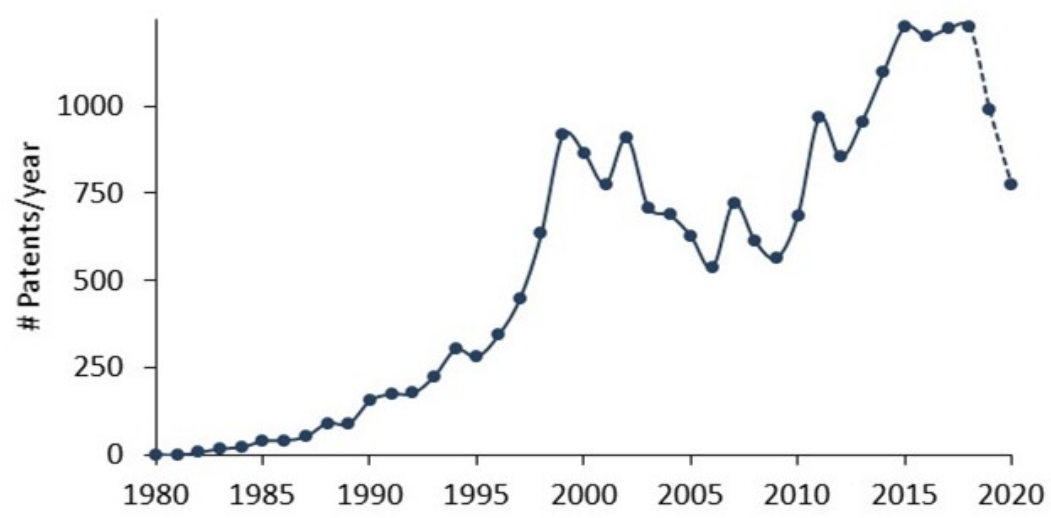
and 27 of the products included

Figure 12. Number of patents issued/year citing NIH funding also associated with published research on drugs approved 2010-2019 or their biological targets. 
in our study. Of the 356 drugs in our study, 311 were included in the current Orange Book release (July 2020) or had a patent in the Orange Book from 1980-present.

Table 8. Percentage of NMEs approved 2010-2019 with patents in the Orange Book funded by NIH-projects also supporting published research on the NME or its biological target.

\begin{tabular}{lccc}
\hline Category & & \# NME & \% NME (3) \\
\hline NMEs 2010-2019 & \# listed in the Orange Book ${ }^{1}$ & 356 & \\
& \# with patent in the Orange Book & 295 & $95 \%$ \\
& \# with NIH-funded patent $^{2}$ & 27 & $8.7 \%$ \\
\hline
\end{tabular}

(1) Includes NMEs with patents in the Orange Book as well as NMEs listed in the Orange Book accessed 7/2020. Does not include CBER drugs and some biologic products removed from the Orange Book in 3/2020. (2) Includes drugs with patents associated with NIH-funded Projects acknowledged in publications on the NME (DRUG) or biological target (TARGET). Many do not include patents from other NIH Projects. (3) Percentage of NMEs with confirmed listings in the Orange Book either from complete patent list or search of 2010-2019 NME approvals performed July 2020.

Of these, $295(95 \%)$ had at least one patent in the Orange Book and 27 had a patent in the Orange Book that was associated with the research identified in this study (Table 8). This fraction is similar to the fraction of drugs with NIH-funded patents in the Orange Book identified using a variety of other methods (Li et al., 2017; Long, 2019; Sampat, 2006; Sampat \& Lichtenberg, 2011; Stevens et al., 2011).

We would caution that the Orange Book only describes patents that are considered to provide marketing exclusivity to FDA-approved products, and represents a legal assessment rather than a business or technical measure of the importance of specific research to product development. Thus, the Orange Book does not necessarily describe all of the intellectual property that may 
have been acquired or licensed in the course of product development, nor all of the intellectual property that may generate royalties from product sales.

\section{Limitations of this research}

There are several major limitations to this research. First, this analysis is limited by the quality of the search algorithms used to identify PMIDs associate with the drug and drug targets. While considerable optimization of the search terms was performed, all three methods utilizedBoolean searches, MeSH subject headings, and Automated Term Mapping — were found to be inconsistent in their sensitivity and specificity. Second, the RePORTER database has incomplete data from some agencies within HHS and there is considerable missing data. In addition, the association of PMID publication dates with specific Funding Years is imperfect. Even with the correction for the lag of publication activity after the last year of a funded Project, up to $10 \%$ of publications are not associated with a specific Project Year or Cost. Third, many of the phase initiation dates were not available from public databases, particularly for Phase 1 . The PharmaProjects database had Phase 1 start dates for only 117 of 232 drugs with accepted TIME fits. While we were able to fill in missing Phase 3 start dates from ClinicalTrials.gov, this database has little or no coverage of clinical trials prior to 2007. Fourth, identification of drugs in the Orange Book requires text matching to brand/trade or generic/ingredient names and can be incomplete. In addition, the association of drugs with patent numbers can be compromised by the removal of patents from the Orange Book at expiration. Finally, as discussed above, we would caution that the NIH funding identified in this research does not represent the per/drug cost of research or development leading to drug approval, but rather the NIH contribution to the ecosystem necessary for enabling this development. 


\section{Conclusions}

This Working Paper quantifies NIH funding for basic or applied research related to each of the new drugs approved by the FDA from 2010-2019. It extends previous analyses of the published research related to drugs approved since 2010 or their biological targets, the NIH-funded Projects (grants) that are acknowledged by these publications, and the Costs that contributed to this research (Cleary et al., 2018; Cleary \& Ledley, 2020). It also examines the maturation of this published research over time, the impact of technological maturation on the efficiency of product development, the nature of the NIH funding supporting this research, and the patents that arise from this work. By detailing the role of the public sector in pharmaceutical innovation, we hope to inform evidence-based policies aimed at accelerating the translation of scientific discoveries for public value, achieving the "highest attainable standard of health" for the public, and provide insights into the public sector's role in value creation and equitable distribution of this value.

This study focuses specifically on the role of the NIH, whose annual budget of $\$ 40$ billion (Sekar, 2020) makes it the largest source of public sector funding for biomedical research in the world. We examine this role in the context of a linear model of innovation. Without critiquing the theoretical or evidential underpinnings of the linear model or its indisputable limitations, this model has had a central place in the formulation of contemporary science and innovation policy. The longstanding distinctions between basic and applied science, the division of basic and applied science between the public and private sectors, and the construction of the Bayh-Dole Act are each reflections of this model.

So too, are some of the critical policy challenges facing biopharmaceutical innovation. These include: the uncertain sustainability of public sector support for basic biomedical research; the 
short-term perspectives and shareholder focus of an increasingly financialized biopharmaceutical industry; the asymmetrical distribution of risk and reward between the public and private sectors; the adverse impact of high drug prices on the affordability and availability of essential medicines and, consequently, public health; and the lack of any effective mechanisms for public oversight over the development enabled by public investment in the earliest stages of scientific and technological innovation.

The overriding observation in this work is the magnitude of the public sector contribution to biopharmaceutical innovation. We identified more than $\$ 230$ billion in NIH grant support (20002019) for research directly related to the 356 drugs approved over the last decade or their biological targets. Of this amount, more than $85 \%$ is classified as basic science related to the biological target, rather than the drug itself.

This is consistent with the expectation embodied in the linear model of innovation that public sector investments are principally focused on the basic science that precedes applied or translational science, rather than product development. Also consistent with this model is the fact that every one of these drugs was brought to market in the United States by a biopharmaceutical company, rather than by an academic, governmental, or non-governmental organization.

The more than $\$ 230$ billion in NIH research support represents a significant fraction of the NIH's total $\$ 586$ billion budget allocation ${ }^{18}$ over this interval and needs to be interpreted in context of the methods used in this analysis. Our method does not focus on discrete developmental milestones such as "target discovery," "target validation," "first synthesis," or "final molecule"

\footnotetext{
${ }^{18}$ National Institutes of Health Actual Total Obligations by Budget Mechanism, FY 2000-FY 2019 (https://officeofbudget.od.nih.gov/pdfs/FY21/spendinghist/Mechanism\%20Detail\%20for\%20NIH\%20FY\%202000-FY\%202019\%20(V).pdf).
} 
as, for example, in the work of Eder et al. (2014), or cast studies of product development (Chakravarthy et al., 2016; Cockburn \& Henderson, 1996, 2000; Nayak et al., 2019). Nor is our analysis restricted to research associated with utility patents (Li et al., 2017; Sampat, 2006, 2009; Sampat \& Lichtenberg, 2011; Stevens et al., 2011). We believe that such methods, which focus specifically on research with applications to specific products, systematically underestimate the public sector's role in supporting basic science, which may not be explicitly associated with any individual product.

Our method aims to describe the public sector's contribution to the broad ecosystem required for biopharmaceutical innovation. It posits that the full body of published research - research comprising dramatic new discoveries, details of biological structures of functions, deconstruction of failed experiments, or duplication of seminal results - contributes to advancing the "forefront of knowledge" that enables drug discovery. This approach recognizes the inherent complexity of biological systems and the need for a systems approach in drug discovery and development (Butcher, Berg, \& Kunkel, 2004). It also recognizes the challenge of anticipating "unknown unknowns," which may not be on the critical path for development, but can contribute to idiosyncratic or irreproducible results in preclinical or clinical studies (Mullane \& Williams, 2015).

Our previous work has shown a consistent relationship between TIME metrics for the maturation of research on discrete biological targets and the efficiency of developing products based on this research (Beierlein, McNamee, \& Ledley, 2017; Beierlein et al., 2017; McNamee \& Ledley, 2012, 2017; McNamee et al., 2017). The present work extends these observations in a substantially larger dataset, showing that none of the products with targets that can be modeled with the TIME model were approved before research on the target passed the analytically 
defined established point of maturation. Moreover, the timelines of clinical development were significantly shorter when clinical trials began only after this point. These data provide further confirmation for the concept that an established body of basic research, defined in this work as publications on a drug's biological target but not the drug itself, is requisite for successfully developing new medicines.

In the linear model of innovation, most of this enabling basic research is largely the domain of the public sector. While the private sector may invest more than a billion dollars in each new product that is successfully developed (DiMasi et al., 2016; Wouters et al., 2020), this work suggests that the public sector contribution to the early stage research that precedes and enables development may be of the same order of magnitude. This is consistent with the role of the public sector as the "early investor" or "investor of first resort" in the earliest stages of biopharmaceutical innovation and value creation (Block \& Keller, 2015; Hopkins \& Lazonick, 2014; Lazonick, 2017; Lazonick \& Mazzucato, 2013; Mazzucato, 2011, 2016; Mazzucato \& Semieniuk, 2017).

Our analysis illustrates the complexity of properly accounting for this public sector investment due to the broad spillovers of public sector research among many different products. Specifically, we observed that PMIDs and Project Years identified in this analysis were associated with more than one new drug, biological target, and even therapeutic area. In fact, the complexity of this analysis arises from the extensive duplication of PMIDs, Project Years, and Costs in the core dataset.

We previously characterized spillovers in a study of the 59 new cancer drugs approved from 2010-2016, in which we found that much of the research directly related to new cancer drugs or 
their biological targets was not funded by the National Cancer Institute, nor was it explicitly identified as "cancer research" in the NIH's Research Condition Disease Categorization system. Rather, we found that much of this research was funded by institutes with disease-specific missions outside of cancer, which had spillover applications to malignant disease (Cleary \& Ledley, 2020). For example, more than $\$ 1$ billion of this research was funded by NIAID, NHLBI, and NIDDK. The present work suggests that such spillovers are also evident in the patents that result from NIH-funded research. Specifically, while only 27 of the drugs in our study had patents in Orange Book patents arising from Projects identified by the DRUG or TARGET searches, many of these patents were listed in the Orange Book in association with drugs that were not part of this study. While we have not fully characterized these products, this is further evidence for the spillover of basic science to many different product opportunities.

One reason for this spillover may be that while the large majority of Projects identified in this study (66\%) supported investigator-initiated Research Projects, these Projects accounted for only $39 \%$ of the total Costs. The combined Costs of Research Program Projects and Centers, Cooperative Agreements, and programs for training and fellowships were greater. These other forms of NIH Project funding do not support investigator-initiated research, but rather provide the infrastructure, technological, human, and organizational capabilities necessary for this work. The Costs that were identified as contributing directly to research related to drugs approved 2010-2019 or their biological targets likely also contributed to research related to many other products as well as future innovations.

The importance of spillovers from a broad foundation of basic research was evident in the rapid identification and Emergency Use Authorization of Remdesivir as a treatment for COVID-19 only four months after the virus was first discovered. Using the same methods employed in this 
study, we demonstrated that the NIH had invested $\$ 6.5$ billion in research that could be related to the biological target for Remdesivir (RNA dependent RNA polymerase) or the pharmaceutical chemistry underlying its chemical structure (a nucleoside analog) even before the virus had been discovered. Significantly, only $12 \%$ of the NIH Costs identified in that study were associated with investigator-initiated Research Projects, while 34\% was for Research Program Projects and Centers and 40\% for Cooperative Agreements (Cleary et al., 2020). Thus, the ability to quickly identify a potential treatment for an unanticipated pathogen represented a spillover of research on other disease indications or drugs as well as the power of a robust, public-sector funded infrastructure for biopharmaceutical innovation.

The importance of spillovers is one reason that investments in basic science are unattractive to pharmaceutical companies. While there is evidence that investment in basic research can provide a positive return on investment (Toole, 2012), the benefits of this investment do not necessarily accrue to the firm that funded the basic work. Similarly, spillovers complicate effective accounting for the public sector contribution to the value created by novel pharmaceutical products.

This analysis highlights the inadequacy of the Bayh-Dole formula for recognizing the public sector contribution in the earliest stages of drug discovery and development and a return on its early-stage investments in biopharmaceutical innovation. This work demonstrates that, despite the fact that we identified NIH funded research directly or indirectly related to every one of the new drugs approved 2010-2019, only $8.6 \%$ of these drugs had patents listed in Orange Book that were explicitly based on this research funding. While many other patents may contribute to the discovery, development, or production of these products, those listed in Orange Book have the 
most tangible impact on the financial returns of the pharmaceutical manufacturer. By conventional measures of financial accounting, these are therefore the most "valuable."

It is harder to recognize the value of non-patented intellectual contributions, such as know-how, or trade secrets, and knowledge placed in the public domain through academic publications. Even if such intellectual property were acquired by a pharmaceutical company, such as by funding academic research or acquisition of an early-stage biotechnology company, it would be treated as an intangible or impaired asset, and recognized as an expense that reduces earnings rather than a valued asset. While this distinction may be semantic in the context of this analysis, such categorizations are completely contrary to the essential role that such intellectual contributions play in enabling drug discovery and development.

Moreover, the Bayh-Dole Act has only limited applicability to advances in biomedical research that do not generate patents. The Bayh-Dole process is initiated by disclosure of a "subject invention" 19 by the recipient of a government grant. This disclosure triggers various reporting requirements to the government, steps towards the patenting and licensing of the invention to industry for development, and certain government rights including the right to practice the invention and "march-in rights" under specified circumstances (Thomas, 2016).

The large majority of the NIH funding identified in this study, however, resulted in publications that were categorized as "basic research." Basic research is not expected to generate results related to the "utility" and "enablement" of any specific products. As much of this research does not generate patentable subject matter, would not trigger a subject invention disclosure, and the

\footnotetext{
19 "Subject invention" is defined in paragraph 401.2(d) of the Bayh-Dole Act: "The term subject invention means any invention of a contractor conceived or first actually reduced to practice in the performance of work under a funding agreement;" https:/grants.nih.gov/grants/bayh-dole.htm\#se37.1.401 18
} 
Bayh-Dole process designed to ensure the creation of public value in the form of both new products and payment to the public sector would not apply. Without addressing the strengths and limitations of Bayh-Dole (Bremer, Allen, \& Latker, 2009), no other mechanism currently exists to govern the translation of scientific discoveries for public value in the form of new products, better health, job creation, or economic growth or provide for government oversight or rights related to this process.

Finally, it should be noted the process of biopharmaceutical innovation is increasingly moving away from the linear model on which Bayh-Dole is based. No mechanisms currently exist for recognizing the value created by public sector investment in translational science (Collins, 2011; Varmus, 2006; Woodcock et al., 2014), the “entrepreneurial university” (Etzkowitz, 2016, 2017), or the triple helix of government-academic-industry collaborations (Leydesdorff \& Etzkowitz, 1998).

Lazonick and Mazzucato (2013) have examined what they term the "Risk/Reward Nexus" of innovation and the mechanisms that lead to asymmetrical sharing of risk and reward between the public and private sector. They illustrate this asymmetry with the observation that the "blockbuster biotech drugs that generated huge returns for both big pharma and biopharma companies reflect control over patent rights to the 'low-hanging fruit' that became available to these companies in the 1980s as a result of decades of NIH funding." Our work highlights both the scale of the "risk" being taken by the public sector as an early investor (Mazzucato, 2011, 2017) in pharmaceutical innovation and the complexity inherent in ensuring that this investment is properly rewarded. It also demonstrates the need for innovative policies that ensure the public sector investments in science are efficiently translated into public value, not only in the form of new products, job creation, and economic growth, but most importantly public health. 
Mazzucato has written that "a better understanding of the role that the state has and can play in the wealth-creation process is the starting point for policy solutions that can increase the rate of wealth creation" (Mazzucato, 2017). We hope that the data in this Working Paper will lead to new insights into evidence-based policy solutions that fully realize the value of public sector investments in pharmaceutical innovation that ensure that they lead to meaningful improvements in health. 


\section{Appendix}

\section{Technology Innovation Maturation Evaluation (TIME) model}

The bibliographic Technology Innovation Maturation Evaluation (TIME) model fits the cumulative number of publications from a technologies Boolean PubMed search results to an exponentiated logistic function as described previously (McNamee, Walsh, \& Ledley, 2017).

The exponentiated logistic function equation has the form:

$$
N=L^{\left(\frac{1}{1+e^{-r\left(t-t_{0}\right.}}\right)}
$$

Where $\mathrm{N}$ is the number of publications, $\mathrm{L}$ is the predicted upper limit of publications, $\mathrm{r}$ is the growth rate, $\mathrm{t}$ is time (year), and $\mathrm{t}_{0}$ is the midpoint of the exponential growth phase. This asymmetric sigmoidal function exhibits the common logistic sigmoidal function over log scales. The parameters were fit to time series publication data using a non-linear least squares implementation of the Levenberg-Marquart algorithm (LMFIT, version 1.0.1). This results in a technology having a symmetric growth phase that is exponential on average. The initiation (Ti) and established (Te) points, representing the beginning and end of this exponential growth of an individual target/technology, or log $\mathrm{N}$ '( $\mathrm{t})_{\max }$ min, can be analytically determined by:

$$
\text { Established, } \text { Initiation }=t_{0} \pm \frac{\operatorname{acosh}(2)}{r}
$$




\section{References}

Abbott, T. A., \& Vernon, J. A. (2007). The cost of US pharmaceutical price regulation: a financial simulation model of R\&D decisions. Managerial and Decision Economics, 28(4-5), 293-306.

Aitken, M., Kleinrock, M. (2019). The Global Use of Medicine in 2019 and Outlook to 2023. Retrieved from https://www.iqvia.com/insights/the-iqvia-institute/reports/the-global-use-of-medicine-in2019-and-outlook-to-2023. [Accessed July 2020].

Archibugi, D., \& Filippetti, A. (2018). The retreat of public research and its adverse consequences on innovation. Technological Forecasting and Social Change, 127, 97-111.

Austin, C. P. (2018). Translating translation. Nature Reviews Drug Discovery, 17(7), 455-456.

Azoulay, P., Fuchs, E., Goldstein, A. P., \& Kearney, M. (2019). Funding breakthrough research: promises and challenges of the "ARPA Model". Innovation Policy and the Economy, 19(1), 69-96.

Balconi, M., Brusoni, S., \& Orsenigo, L. (2010). In defence of the linear model: An essay. Research Policy, 39(1), 1-13.

Beaver, J. A., Howie, L. J., Pelosof, L., Kim, T., Liu, J., Goldberg, K. B., ... Kluetz, P. G. (2018). A 25Year Experience of US Food and Drug Administration Accelerated Approval of Malignant Hematology and Oncology Drugs and Biologics: A Review. JAMA Oncology, 4(6), 849-856. doi:10.1001/jamaoncol.2017.5618.

Beierlein, J. M., McNamee, L. M., \& Ledley, F. D. (2017). As technologies for nucleotide therapeutics mature, products emerge. Molecular Therapy-Nucleic Acids, 9, 379-386.

Beierlein, J. M., McNamee, L. M., Walsh, M. J., Kaitin, K. I., DiMasi, J. A., \& Ledley, F. D. (2017). Landscape of innovation for cardiovascular pharmaceuticals: From basic science to new molecular entities. Clinical Therapeutics, 39(7), 1409-1425.

Beierlein, J. M., McNamee, L. M., Walsh, M. J., \& Ledley, F. D. (2015). Patterns of innovation in Alzheimer's disease drug development: a strategic assessment based on technological maturity. Clinical Therapeutics, 37(8), 1643-1651.

Block, F. L., \& Keller, M. R. (2015). State of innovation: the US government's role in technology development: Routledge.

Boat, T. F., \& Field, M. J. (2011). Rare diseases and orphan products: Accelerating research and development: National Academies Press.

Boyack, K. W., \& Jordan, P. (2011). Metrics associated with NIH funding: a high-level view. Journal of the American Medical Informatics Association, 18(4), 423-431.

Bremer, H., Allen, J., \& Latker, N. J. (2009). The US Bayh-Dole Act and revisionism redux. Industry and Higher Education, 23(5), 351-366. 
Bush, V. (1945). The Endless Frontier, Report to the President on a Program for Postwar Scientific Research. Retrieved from https://www.nsf.gov/od/lpa/nsf50/vbush1945.htm. [Accessed July 2020].

Butcher, E. C., Berg, E. L., \& Kunkel, E. J. (2004). Systems biology in drug discovery. Nature Biotechnology, 22(10), 1253-1259.

CFR. (2010). Code of Federal Regulations, Title 37 Part 401 Rights to inventions made by nonprofit organizations and small business firms under government grants, contracts, and cooerative agreements, Code of Federal Regulations. Retrieved from https://www.govinfo.gov/content/pkg/CFR-2010-title37-vol1/pdf/CFR-2010-title37-vol1part401.pdf. [Accessed July 2020].

Chakravarthy, R., Cotter, K., DiMasi, J., Milne, C.-P., \& Wendel, N. (2016). Public-and private-sector contributions to the research and development of the most transformational drugs in the past 25 years: from theory to therapy. Therapeutic Innovation \& Regulatory Science, 50(6), 759-768.

Chambers, J. D., Thorat, T., Wilkinson, C. L., \& Neumann, P. J. (2017). Drugs cleared through the FDA's expedited review offer greater gains than drugs approved by conventional process. Health Affairs, 36(8), 1408-1415.

Christensen, C. M. (1992). Exploring the limits of the technology S-curve. Part I: component technologies. Production and Operations Management, 1(4), 334-357.

Christensen, C. M. (1997). The Innovator's Dilemma: When New Technologies Cause Great Firms to Fail. . Boston, MA: Harvard Business School Press.

Clausing, D., \& Holmes, M. (2010). Technology readiness. Research-Technology Management, 53(4), $52-59$.

Cleary, E. G., Beierlein, J. M., Khanuja, N. S., McNamee, L. M., \& Ledley, F. D. (2018). Contribution of NIH funding to new drug approvals 2010-2016. Proceedings of the National Academy of Sciences, 115(10), 2329-2334.

Cleary, E. G., Jackson, M. J., Folchman-Wagner, Z., \& Ledley, F. D. (2020). Foundational research and NIH funding enabling Emergency Use Authorization of remdesivir for COVID-19. medRxiv.

Cleary, E. G., \& Ledley, F. D. (2020). NIH funding for research underlying new cancer therapies. The Lancet. Oncology, 21(6), 755-757.

Cockburn, I., \& Henderson, R. (1996). Public-private interaction in pharmaceutical research. Proceedings of the National Academy of Sciences, 93(23), 12725-12730.

Cockburn, I. M., \& Henderson, R. M. (2000). Publicly funded science and the productivity of the pharmaceutical industry. Innovation Policy and the Economy, 1, 1-34.

Collins, F. S. (2011). Reengineering translational science: the time is right. Science Translational Medicine, 3(90), 90cm17. https://stm.sciencemag.org/content $/ 3 / 90 / 90 \mathrm{~cm} 17$.

Collins, F. S., Anderson, J. M., Austin, C. P., Battey, J. F., Birnbaum, L. S., Briggs, J. P., . . Fauci, A. S. (2016). Basic science: bedrock of progress. Science, 351(6280), 1405-1405. 
Comroe, J. H., \& Dripps, R. D. (1978). Scientific basis for the support of biomedical science. Biomedical Scientists and Public Policy (pp. 15-33): Springer.

Darrow, J. J., Avorn, J., \& Kesselheim, A. S. (2014). New FDA breakthrough-drug categoryimplications for patients: Mass Medical Soc. Retrieved from https://www.nejm.org/doi/full/10.1056/NEJMhle1311493. [Accessed July 2020].

Darrow, J. J., Avorn, J., \& Kesselheim, A. S. (2020). FDA approval and regulation of pharmaceuticals, 1983-2018. JAMA, 323(2), 164-176.

Deb, C., \& Curfman, G. (2020). Relentless prescription drug price increases. JAMA, 323(9), 826-828.

DeVito, N. J., Bacon, S., \& Goldacre, B. (2020). Compliance with legal requirement to report clinical trial results on ClinicalTrials. gov: a cohort study. The Lancet, 395(10221), 361-369.

DiMasi, J. A., Grabowski, H. G., \& Hansen, R. W. (2016). Innovation in the pharmaceutical industry: new estimates of R\&D costs. Journal of Health Economics, 47, $20-33$.

DiMasi, J. A., Hansen, R. W., \& Grabowski, H. G. (2003). The price of innovation: new estimates of drug development costs. Journal of Health Economics, 22(2), 151-185.

Eder, J., Sedrani, R., \& Wiesmann, C. (2014). The discovery of first-in-class drugs: origins and evolution. Nature Reviews Drug Discovery, 13(8), 577-587.

Edgerton, D. (2004) 'The linear model' did not exist: Reflections on the history and historiography of science and research in industry in the twentieth century. Retrieved from https://www.researchgate.net/publication/313772710_The_Linear_Model'_Did_Not_Exist_Refle ctions_on the History and Historiography_of_Science_and Research_in_Industry_in the Twe ntieth Century. [Accessed July 2020].

Etzkowitz, H. (2016). The entrepreneurial university: vision and metrics. Industry and Higher Education, $30(2), 83-97$.

Etzkowitz, H. (2017). Innovation lodestar: The entrepreneurial university in a stellar knowledge firmament. Technological Forecasting and Social Change, 123, 122-129.

FCST. (1968). Effects of Government Policy on Commercial Utilization and Business Competition, Government patent policy study, final report. Federal Council for Science and Technology, 4.

Foster, R. N. (1982). Effective R\&D operations in the '80s: Boosting the payoff from R\&D. Research Management, 25(1), 22-27.

GAO. (1999). BEST PRACTICES: Better Management of Technology Development Can Improve Weapon System Outcomes. Retrieved from https://www.gao.gov/archive/1999/ns991620.pdf. [Accessed July 2020].

Giaccotto, C., Santerre, R. E., \& Vernon, J. A. (2005). Drug prices and research and development investment behavior in the pharmaceutical industry. The Journal of Law and Economics, 48(1), $195-214$. 
Gillum, L. A., Gouveia, C., Dorsey, E. R., Pletcher, M., Mathers, C. D., McCulloch, C. E., \& Johnston, S. C. (2011). NIH disease funding levels and burden of disease. PLoS ONE, 6(2), e16837.

Godin, B. (2006). The linear model of innovation the historical construction of an analytical framework. Science, Technology \& Human Values, 31(6), 639-667.

Godin, B., \& Lane, J. P. (2013). Pushes and pulls: Hi (S) tory of the demand pull model of innovation. Science, Technology, \& Human Values, 38(5), 621-654.

Golec, J., Hegde, S., \& Vernon, J. A. (2010). Pharmaceutical R\&D spending and threats of price regulation. Journal of Financial and Quantitative Analysis, 45(1), 239-264.

Grabowski, H. G., \& Wang, Y. R. (2006). The quantity and quality of worldwide new drug introductions, 1982-2003. Health Affairs, 25(2), 452-460.

Gross, C. P., Anderson, G. F., \& Powe, N. R. (1999). The relation between funding by the National Institutes of Health and the burden of disease. New England Journal of Medicine, 340(24), 18811887.

Gyawali, B., Hey, S. P., \& Kesselheim, A. S. (2019). Assessment of the clinical benefit of cancer drugs receiving accelerated approval. JAMA Internal Medicine, 179(7), 906-913.

Haber, D. A., Gray, N. S., \& Baselga, J. (2011). The evolving war on cancer. Cell, 145(1), 19-24.

Hafner, K., \& Lyon, M. (1998). Where wizards stay up late: The origins of the Internet: Simon and Schuster.

Hernandez, I., San-Juan-Rodriguez, A., Good, C. B., \& Gellad, W. F. (2020). Changes in list prices, net prices, and discounts for branded drugs in the US, 2007-2018. JAMA, 323(9), 854-862.

Hopkins, M., \& Lazonick, W. (2014). Who invests in the high-tech knowledge base? Institute for New Economic Thinking Working Paper Series(14). Retrieved from https://www.ineteconomics.org/research/research-papers/who-invests-in-the-high-techknowledge-base. [Accessed July 2020].

Hourihan, M. (2018). Does the long-term fiscal picture mean trouble for science and innovation? New projections raise the prospects of stagnant funding for $R \& D$. Retrieved from https://www.aaas.org/news/does-long-term-fiscal-picture-mean-trouble-science-and-innovation. [Accessed July 2020].

Hwang, T. J., Darrow, J. J., \& Kesselheim, A. S. (2017). The FDA's expedited programs and clinical development times for novel therapeutics, 2012-2016. JAMA, 318(21), 2137-2138.

Kaitin, K. I., Bryant, N. R., \& Lasagna, L. (1993). The role of the research-based pharmaceutical industry in medical progress in the United States. The Journal of Clinical Pharmacology, 33(5), 412-417.

Kesselheim, A. S., Avorn, J., \& Sarpatwari, A. (2016). The high cost of prescription drugs in the United States: Origins and prospects for reform. JAMA, 316(8), 858-871.

Kesselheim, A. S., Wang, B., Franklin, J. M., \& Darrow, J. J. (2015). Trends in utilization of FDA expedited drug development and approval programs, 1987-2014: cohort study. BMJ, 351, h4633. 
Kinch, M. S., Haynesworth, A., Kinch, S. L., \& Hoyer, D. (2014). An overview of FDA-approved new molecular entities: 1827-2013. Drug Discovery Today, 19(8), 1033-1039.

Lanthier, M., Miller, K. L., Nardinelli, C., \& Woodcock, J. (2013). An improved approach to measuring drug innovation finds steady rates of first-in-class pharmaceuticals, 1987-2011. Health Affairs, 32(8), 1433-1439.

Lauer, M. (2016). NIH's commitment to basic science. Retrieved from https://nexus.od.nih.gov/all/2016/03/25/nihs-commitment-to-basic-science/. [Accessed July 2020].

Lazonick, W. (2017). Innovative enterprise and sustainable prosperity. Retrieved from https:/www.ineteconomics.org/uploads/papers/Lazonick-Innovative-Enterprise-and-SustainableProsperity-INET-20171010.pdf. [Accessed July 2020].

Lazonick, W., Hopkins, M., Jacobson, K., Sakinç, M. E., \& Tulum, Ö. (2017). US pharma's financialized business model. Institute for New Economic Thinking Working Paper Series(60). Retrieved from https://www.ineteconomics.org/uploads/papers/WP 60-Lazonick-et-al-US-Pharma-BusinessModel.pdf. [Accessed July 2020].

Lazonick, W., \& Mazzucato, M. (2013). The risk-reward nexus in the innovation-inequality relationship: who takes the risks? Who gets the rewards? Industrial and Corporate Change, 22(4), 1093-1128.

Lazonick, W., Mazzucato, M., \& Tulum, Ö. (2013). Apple's changing business model: What should the world's richest company do with all those profits? Paper presented at the Accounting Forum. Retrieved from https://doi.org/10.1016/j.accfor.2013.07.002. [Accessed July 2020].

Lazonick, W., \& Tulum, Ö. (2011). US biopharmaceutical finance and the sustainability of the biotech business model. Research Policy, 40(9), 1170-1187.

Ledley, F., McNamee, L., Uzdil, V., \& Morgan, I. (2014). Why commercialization of gene therapy stalled; examining the life cycles of gene therapy technologies. Gene therapy, 21(2), 188-194.

Ledley, F. D., McCoy, S. S., Vaughan, G., \& Cleary, E. G. (2020). Profitability of large pharmaceutical companies compared with other large public companies. JAMA, 323(9), 834-843.

Leydesdorff, L. (2000). The triple helix: an evolutionary model of innovations. Research Policy, 29(2), $243-255$.

Leydesdorff, L., \& Etzkowitz, H. (1998). The triple helix as a model for innovation studies. Science and Public Policy, 25(3), 195-203.

Li, D., Azoulay, P., \& Sampat, B. N. (2017). The applied value of public investments in biomedical research. Science, 356(6333), 78-81.

Lichtenberg, F. R. (2005). The impact of new drug launches on longevity: Evidence from longitudinal, disease-level data from 52 countries, 1982-2001. International Journal of Health Care Finance and Economics, 5(1), 47-73. 
Lichtenberg, F. R. (2012). The effect of pharmaceutical innovation on the functional limitations of elderly Americans: Evidence from the 2004 National Nursing Home Survey: Emerald Group Publishing Limited. Retrieved from https://www.nber.org/papers/w17750.pdf. [Accessed July 2020].

Lichtenberg, F. R. (2014a). Pharmaceutical innovation and longevity growth in 30 developing and highincome countries, 2000-2009. Health Policy and Technology, 3(1), 36-58.

Lichtenberg, F. R. (2014b). The impact of pharmaceutical innovation on disability days and the use of medical services in the United States, 1997-2010. Journal of Human Capital, 8(4), 432-480.

Loise, V., \& Stevens, A. J. (2010). The Bayh-Dole Act turns 30. Science Translational Medicine, 2(52), $52 \mathrm{~cm} 27-52 \mathrm{~cm} 27$.

Long, G. (2019). Federal government-interest patent disclosures for recent top-selling drugs. Journal of Medical Economics, 22(12), 1261-1267.

Martin, L., Hutchens, M., \& Hawkins, C. (2017). Clinical trial cycle times continue to increase despite industry efforts: Nature Publishing Group. Retrieved from https://www.nature.com/articles/nrd.2017.21. [Accessed July 2020].

Mazzucato, M. (2011). The entrepreneurial state. Soundings, 49(49), 131-142.

Mazzucato, M. (2016). An entrepreneurial society needs an entrepreneurial state. Harvard Business Review. Retrieved from https://hbr.org/2016/10/an-entrepreneurial-society-needs-anentrepreneurial-state. [Accessed July 2020].

Mazzucato, M. (2017). Wealth creation and the entrepreneurial state: Building symbiotic public-private partnerships. Institute for New Economic Thinking.

Mazzucato, M., \& Semieniuk, G. (2017). Public financing of innovation: New questions. Oxford Review of Economic Policy, 33(1), 24-48.

McNamee, L. M., \& Ledley, F. D. (2012). Patterns of technological innovation in biotech. Nature Biotechnology, 30(10), 937-943.

McNamee, L. M., \& Ledley, F. D. (2017). Modeling timelines for translational science in cancer; the impact of technological maturation. PLoS ONE, 12(3), e0174538.

McNamee, L. M., Walsh, M. J., \& Ledley, F. D. (2017). Timelines of translational science: from technology initiation to FDA approval. PLoS ONE, 12(5), e0177371.

Mervis, J. (2020a). Trump's new budget cuts all but a favored few science programs: American Association for the Advancement of Science. Retrieved from https://www.sciencemag.org/news/2020/02/trump-s-new-budget-cuts-all-favored-few-scienceprograms. [Accessed July 2020].

Mervis, J. (2020b). Congress again rejects Trump cuts, smiles on science agencies. American Association for the Advancement of Science. Retrieved from https://science.sciencemag.org/content/367/6473/13.long. [Accessed July 2020]. 
Miller, K. L., \& Lanthier, M. (2015). Regulatory watch: Innovation in biologic new molecular entities: 1986-2014. Nature Publishing Group. Retrieved from https://www.nature.com/articles/nrd4535. [Accessed July 2020].

Moffat, J. G., Vincent, F., Lee, J. A., Eder, J., \& Prunotto, M. (2017). Opportunities and challenges in phenotypic drug discovery: An industry perspective. Nature Reviews Drug Discovery, 16(8), 531-543.

Montalban, M., \& Sakinç, M. E. (2011). How financialization shapes productive models in pharmaceutical industry: The domination and contradictions of the blockbuster productive model. Université de Bordeaux GREThA UMR CNRS, 5113, 35p.

Montalban, M., \& Sakinç, M. E. (2013). Financialization and productive models in the pharmaceutical industry. Industrial and Corporate Change, 22(4), 981-1030.

Moses, H., Matheson, D. H., Cairns-Smith, S., George, B. P., Palisch, C., \& Dorsey, E. R. (2015). The anatomy of medical research: US and international comparisons. JAMA, 313(2), 174-189.

Mostaghim, S. R., Gagne, J. J., \& Kesselheim, A. S. (2017). Safety related label changes for new drugs after approval in the US through expedited regulatory pathways: Retrospective cohort study. $B M J, 358, \mathrm{j} 3837$.

Mowery, D. C., \& Sampat, B. N. (2004). The Bayh-Dole Act of 1980 and university-industry technology transfer: A model for other OECD governments? The Journal of Technology Transfer, 30(1), $115-127$.

Mullane, K., \& Williams, M. (2015). Unknown unknowns in biomedical research: does an inability to deal with ambiguity contribute to issues of irreproducibility? Biochemical Pharmacology, 97(2), $133-136$.

Naci, H., Smalley, K. R., \& Kesselheim, A. S. (2017). Characteristics of preapproval and postapproval studies for drugs granted accelerated approval by the US Food and Drug Administration. JAMA, $318(7), 626-636$.

Nahler, G. (2009). Anatomical therapeutic chemical classification system (ATC). Dictionary of Pharmaceutical Medicine: Springer.

Nathan, D. G., \& Nathan, D. M. (2016). Eulogy for the clinical research center. The Journal of Clinical Investigation, 126(7), 2388-2391.

Nathan, D. G., \& Wilson, J. D. (2003). Clinical research and the NIH-A report card. New England Journal of Medicine, 349(19), 1860-1860.

NAS. (2018). Making medicines affordable: A national imperative: National Academies Press.

Nayak, R. K., Avorn, J., \& Kesselheim, A. S. (2019). Public sector financial support for late stage discovery of new drugs in the United States: cohort study. BMJ, 367, 15766.

Neumann, P. J., Sandberg, E.A., Bell, C.M., Stone, P.W., Chapman, R.H. (2000). Are pharmaceuticals cost-effective? A review of the evidence. Health Affairs, 19(2), 92-109. 
NIH. (2007). National Institutes of Health. Definitions under Subsection 1 (Research Objectives), Section I (Funding Opportunity Description), Part II (Full Text of Announcement), of RFA-RM-07-007: Institutional Clinical and Translational Science Award (U54) Mar2007. Retrieved from https://grants.nih.gov/grants/guide/rfa-files/rfa-rm-07-007.html. [Accessed July 2020].

NRC. (2009). Venture funding and the NIH SBIR program: National Academies Press.

NRC. (2011). Managing University intellectual property in the public interest: National Academies Press.

NSF. (2018). Definitions of Research and Development: An Annotated Compilation of Official Sources. Retrieved from https://www.nsf.gov/statistics/randdef/rd-definitions.pdf. [Accessed July 2020].

Padula, W. V. (2019). State and federal policy solutions to rising prescriptions drug prices in the US. $J$. Health Care L. \& Pol'y, 22, 15.

Pammolli, F., Magazzini, L., \& Riccaboni, M. (2011). The productivity crisis in pharmaceutical R\&D. Nat. Rev. Drug Discov., 10(6), 428-438. doi:10.1038/nrd3405

Patridge, E. V., Gareiss, P. C., Kinch, M. S., \& Hoyer, D. W. (2015). An analysis of original research contributions toward FDA-approved drugs. Drug Discovery Today, 20(10), 1182-1187.

Reichert, J. M., \& Milne, C.-P. (2002). Public and private sector contributions to the discovery and development of "impact" drugs. American Journal of Therapeutics, 9(6), 543-555.

Sachs, R. (2019). Prescription Drug Legislation In Congress: An Update. Retrieved from https://www.healthaffairs.org/do/10.1377/hblog20191211.802562/full/. [Accessed July 2020].

Sampat, B. N. (2006). Patenting and US academic research in the 20th century: The world before and after Bayh-Dole. Research Policy, 35(6), 772-789.

Sampat, B. N. (2009). Academic patents and access to medicines in developing countries. American Journal of Public Health, 99(1), 9-17.

Sampat, B. N. (2012). Mission-oriented biomedical research at the NIH. Research Policy, 41(10), 17291741.

Sampat, B. N., \& Lichtenberg, F. R. (2011). What are the respective roles of the public and private sectors in pharmaceutical innovation? Health Affairs, 30(2), 332-339.

Scannell, J. W., Blanckley, A., Boldon, H., \& Warrington, B. (2012). Diagnosing the decline in pharmaceutical R\&D efficiency. Nature Reviews Drug Discovery, 11(3), 191-200.

Schumock, G. T., Stubbings, J., Hoffman, J. M., Wiest, M. D., Suda, K. J., Rim, M. H., . . Clark, J. S. (2019). National trends in prescription drug expenditures and projections for 2019. American Journal of Health-System Pharmacy, 76(15), 1105-1121.

Sekar, K. (2020). National Institutes of Health (NIH) Funding: FY1995-FY2021. Retrieved from Congressional Research Service: https://fas.org/sgp/crs/misc/R43341.pdf.

Steedman, M., Taylor, K. (2020). Ten years on; Measuring the return from pharmaceutical innovation 2019. Retrieved from https://www2.deloitte.com/content/dam/Deloitte/uk/Documents/life- 
sciences-health-care/deloitte-uk-ten-years-on-measuring-return-on-pharma-innovation-report2019.pdf. [Accessed July 2020].

Stevens, A. J. (2004). The enactment of Bayh-Dole. The Journal of Technology Transfer, 29(1), 93-99.

Stevens, A. J., Jensen, J. J., Wyller, K., Kilgore, P. C., Chatterjee, S., \& Rohrbaugh, M. L. (2011). The role of public-sector research in the discovery of drugs and vaccines. New England Journal of Medicine, 364(6), 535-541.

Stokes, D. E. (2011). Pasteur's quadrant: Basic science and technological innovation.: Brookings Institution Press.

Thomas, J. R. (2016). March-In Rights Under the Bayh-Dole Act. Retrieved from https://fas.org/sgp/crs/misc/R44597.pdf. [Accessed July 2020].

Toole, A. A. (2012). The impact of public basic research on industrial innovation: Evidence from the pharmaceutical industry. Research Policy, 41(1), 1-12.

Tralau-Stewart, C. J., Wyatt, C. A., Kleyn, D. E., \& Ayad, A. (2009). Drug discovery: new models for industry-academic partnerships. Drug Discov. Today, 14(1-2), 95-101.

doi:10.1016/j.drudis.2008.10.003.

Treasure, C. (2016). Do March-in Rights Ensure Low-Cost Access to Medical Products Arising From Federally-Funded Research? A Qualitative Study. Retrieved from https://dash.harvard.edu/bitstream/handle/1/27007723/TREASUREDOCTOROFMEDICINETHESIS-2016.pdf? sequence=3. [Accessed July 2020].

Tulum, Ö., \& Lazonick, W. (2018). Financialized corporations in a national innovation system: The US pharmaceutical industry. International Journal of Political Economy, 47(3-4), 281-316.

Vadola, L. A., Pond, M. A., Winter-Vann, A., \& Whitsell, R. (2017). Faster approvals?: Trends in the use of FDA's expedited approval programs for oncology medications. American Society of Clinical Oncology. Retrieved from https://ascopubs.org/doi/abs/10.1200/JCO.2017.35.15 suppl.e18270. [Accessed July 2020].

Varmus, H. (2006). The new era in cancer research. Science, 312(5777), 1162-1165.

Vernon, J. A. (2005). Examining the link between price regulation and pharmaceutical R\&D investment. Health Economics, 14(1), 1-16.

Wang, L., Plump, A., \& Ringel, M. (2015). Racing to define pharmaceutical R\&D external innovation models. Drug Discovery Today, 20(3), 361-370.

WHO. (2006). Constitution of the World Health Organization. 1946 (as amended 1977, 1984, 1994, 2005). Retrieved from https://www.who.int/governance/eb/who_constitution_en.pdf. [Accessed July 2020].

Woloshin, S., Schwartz, L. M., White, B., \& Moore, T. J. (2017). The fate of FDA postapproval studies. New England Journal of Medicine, 377(12), 1114-1117. 
Wong, C. H., Siah, K. W., \& Lo, A. W. (2019). Estimation of clinical trial success rates and related parameters. Biostatistics, 20(2), 273-286.

Woodcock, J., Brumfield, M., Gill, D., \& Zerhouni, E. (2014). The driving role of consortia on the critical path to innovative therapies: Launched a decade ago, the US Food and Drug Administration's Critical Path Initiative has helped catalyse the formation of many consortia focused on drug development challenges. Nature Reviews Drug Discovery, 13(11), 781-782.

Wouters, O. J., McKee, M., \& Luyten, J. (2020). Estimated research and development investment needed to bring a new medicine to market, 2009-2018. JAMA, 323(9), 844-853.

Zerhouni, E. (2007). Translational research: moving discovery to practice. Clinical Pharmacology \& Therapeutics, 81(1), 126-128.

Zycher, B., DiMasi, J. A., \& Milne, C.-P. (2010). Private sector contributions to pharmaceutical science: thirty-five summary case histories. American Journal of Therapeutics, 17(1), 101-120. 